\title{
Infrared Spectroscopy of Matrix-Isolated Polycyclic Aromatic Compounds and Their Ions. 6. Polycyclic Aromatic Nitrogen Heterocycles
}

\author{
A. L. Mattioda, ${ }^{*}{ }^{\dagger}$ D. M. Hudgins, ${ }^{\dagger}$ C. W. Bauschlicher, Jr, ${ }^{\dagger}$ M. Rosi, ${ }^{\dagger}$ and L. J. Allamandola ${ }^{\dagger}$ \\ NASA Ames Research Center, MS 245-6, Moffett Field, California 94035, and CNR Institute for Molecular \\ Science and Technologies, clo Department of Chemistry, University of Perugia, 06123 Perugia, Italy
}

Received: August 22, 2002

\begin{abstract}
The matrix-isolation technique has been employed to measure the mid-infrared spectra of several polycyclic aromatic nitrogen heterocycles in both neutral and cationic forms. The species studied include: 7,8benzoquinoline $\left(\mathrm{C}_{13} \mathrm{H}_{9} \mathrm{~N}\right)$, 2-azapyrene $\left(\mathrm{C}_{15} \mathrm{H}_{9} \mathrm{~N}\right)$, 1- and 2- azabenz $[a]$ anthracene $\left(\mathrm{C}_{17} \mathrm{H}_{11} \mathrm{~N}\right)$, and 1-, 2-, and 4-azachrysene (also $\mathrm{C}_{17} \mathrm{H}_{11} \mathrm{~N}$ ). The experimentally measured band frequencies and intensities for each molecule are tabulated and compared with their calculated values computed using density functional theory at the B3LYP/4-31G level. The overall agreement between experiment and theory is good, in keeping with previous investigations involving the parent aromatic hydrocarbons. Several interesting spectroscopic trends are found to accompany nitrogen substitution into the aromatic framework of these compounds. For the neutral species, the nitrogen atom produces a significant increase in the total integrated infrared intensity across the 1600$1100 \mathrm{~cm}^{-1}$ region and plays an essential role in the molecular vibration that underlies an uncharacteristically intense, discrete feature that is observed near $1400 \mathrm{~cm}^{-1}$ in the spectra of 7,8-benzoquinoline, 1-azabenz[a]anthracene, and 4-azachrysene. The origin of this enhanced infrared activity and the nature of the $1400 \mathrm{~cm}^{-1}$ vibrational mode are explored. As a secondary result of the computations, the computed dipole moments and rotational constants for the species under study are reported. The dipole moments calculated are significantly stronger than those of the parent PAH and in principle could facilitate interstellar detection of these PAH related compounds.
\end{abstract}

\section{Introduction}

Motivated in large part by their emerging importance in the field of astrophysics, the past decade has witnessed a renaissance in the study of the fundamental molecular and spectroscopic properties of polycyclic aromatic hydrocarbons (PAHs). Of particular interest has been the prominent and ubiquitous interstellar infrared emission signature that belies the presence of this class of compounds in a surprising variety of very disparate astronomical objects throughout our galaxy. ${ }^{1}$ Nitrogen is the fourth most abundant, chemically reactive element in the interstellar environment. Therefore, it is reasonable to assume that a fraction of interstellar PAH species will contain nitrogen. This assumption is given further credence by nitrogen's ability to participate in the aromatic network of a PAH molecule. The drive to better understand the role of PAHs in the interstellar medium has catalyzed the establishment of comprehensive theoretical and experimental programs to study the fundamental spectroscopic characteristics of these species in both neutral and ionized forms. On the theoretical side, beginning with the work of Langhoff ${ }^{2}$, the use of density functional theory (DFT) to calculate the harmonic frequencies and intensities of PAH species has revolutionized quantum chemical analyses of large molecular systems. This, coupled with rapid advances in computational power, has facilitated calculation of the infrared spectra of a wide range of $\mathrm{PAHs}^{2-4}$ many of which are not accessible with current experimental techniques. ${ }^{5}$ On the experimental side, the matrix isolation technique has been

* To whom correspondence should be addressed.

NASA Ames Research Center.

$\doteqdot$ University of Perugia. particularly prolific in providing the infrared absorption spectra of many PAH species under conditions relevant to the astrophysical problem. ${ }^{6-8}$ The DFT calculations provide a valuable calibration of the magnitude of matrix effects in the experimental data, whereas the experimental data provide a check for the effects of symmetry breaking which can seriously impact the accuracy of the DFT calculations. ${ }^{9}$

In addition to the matrix experiments and DFT calculations, interest in molecular dynamics coupled with the critical data needs in the neighboring field of astrophysics have also driven the development of additional, elegant experimental techniques designed to explore the infrared properties of PAHs in the gasphase. Using their SPIRES (single photon infrared emission spectroscopy) technique, Saykally and co-workers have directly measured the infrared emission spectra from several vibrationally excited, neutral, and ionized PAHs in the gas phase under conditions relevant to those of the interstellar emitters. ${ }^{10}$ This work has yielded unique insight into the fundamental photophysics of infrared fluorescence in PAHs and PAH ions, the mechanism believed to drive the observed interstellar infrared emission and govern the interstellar UV/vis-to-IR conversion process. Working independently, Meijer and coworkers have pioneered a sensitive cluster-dissociation technique for directly measured the vibrational absorption spectrum of cold, gas-phase PAH cations in a free jet expansion using the tunable infrared beam of a free-electron laser. ${ }^{11}$ This work has revealed important details about the vibrational properties of isolated gas-phase PAH cations and provides a direct experimental measure of the matrix perturbations on the vibrational spectra of PAH ions. Overall, the agreement between the data 
provided by these latter techniques and those of the matrix experiments are surprisingly good. Together, these two new techniques provide further evidence supporting the interstellar PAH model and the utility of matrix isolation infrared absorption data for addressing the astrophysical problem.

The Astrochemistry laboratory at NASA Ames Research Center has an ongoing program to study the infrared spectroscopic properties of PAHs and PAH ions using a combination of matrix-isolation measurements and DFT calculations. Previous papers in this series ${ }^{8}$ have explored a variety of size and structural effects on the spectra of these species. These data are also available on the Internet at http://www.astrochem.org/ pahdata/index.html. This paper explores the effects of incorporating a nitrogen atom in the aromatic network of several polycyclic aromatic species. To our knowledge, this is the first time the low-temperature, matrix-isolated IR spectra of these polycyclic aromatic nitrogen heterocycles (alternatively PANHs, $\mathrm{N}$-PAHs, or aza-PAHs) and includes the following species in both their neutral and ionized forms: 7,8-benzoquinoline $\left(\mathrm{C}_{13} \mathrm{H}_{9} \mathrm{~N}\right), 2$-azapyrene $\left(\mathrm{C}_{15} \mathrm{H}_{9} \mathrm{~N}\right), 1$ - and 2-azabenz[a] anthracene, and 1-, 2-, and 4-azachrysene (all $\left.\mathrm{C}_{17} \mathrm{H}_{11} \mathrm{~N}\right)$ are presented. The structures of these species are shown in Figure 1.

\section{Experimental and Theoretical Methods}

A. Experimental. The matrix isolation infrared spectroscopy techniques employed in these studies have been described in detail previously ${ }^{8 \mathrm{~b}, \mathrm{e}}$ and will be summarized here only briefly. Matrix isolated PANH samples were prepared by vapor codeposition of the species of interest with an over abundance of argon onto a $14 \mathrm{~K}$ CsI window suspended in a high-vacuum chamber ( $p<10^{-8}$ Torr). The PANH samples were vaporized from heated Pyrex tubes while argon was admitted through an adjacent length of $\mathrm{N}_{2}(l)$-trapped copper tubing. Deposition temperatures for the PANHs studied were as follows: 7,8benzoquinoline, room temperature; 2 -azapyrene, $40{ }^{\circ} \mathrm{C}$; 1 -azabenz $[a]$ anthracene, $81{ }^{\circ} \mathrm{C}$; 2-azabenz $[a]$ anthracene, $98{ }^{\circ} \mathrm{C}$; 1-azachrysene, $97{ }^{\circ} \mathrm{C}$; 2-azachrysene, $107{ }^{\circ} \mathrm{C}$; and 4-azachrysene, $104{ }^{\circ} \mathrm{C}$. Because of its relatively high volatility, 7,8benzoquinoline was deposited through a short length of heated copper tubing fitted with a valve (Whitey model \#SS-8BK). The valve was opened to admit the PANH vapor during deposition but otherwise was kept closed to prevent a continuous flow of this vapor into the sample chamber throughout the experiment. Although 2-azapyrene required a temperature of $40{ }^{\circ} \mathrm{C}$ to achieve the proper deposition rate, it exhibited an appreciable vapor pressure at room temperature. Thus, the experimental setup utilized for the 7,8-benzoquinoline investigation was employed in the 2-azapyrene study. Estimates based on the characteristic band intensities of PAHs and the calibrated argon deposition rate place the $\mathrm{Ar} / \mathrm{PANH}$ ratio in these experiments in excess of 1000/1. ${ }^{8 \mathrm{e}} 7,8$-Benzoquinoline $(98+\%)$ was obtained from Sigma/Aldrich Chemical Co. The remaining PANH samples used in these experiments were obtained from the National Cancer Institute's Chemical Carcinogen Reference Standard Repository operated by the Midwest Research Institute. All samples are of unspecified purity; however, the absence of any notable discrepant spectral features between the theoretical and experimental spectra indicate impurity levels are no more than a few percent.

Spectra from 6000 to $500 \mathrm{~cm}^{-1}$ were measured on either a Nicolet 740 or a Digilab Excalibur FTS 4000 FTIR spectrometer using a $\mathrm{KBr}$ beam splitter and $\mathrm{N}_{2}(l)$-cooled MCT detector. Each spectrum represents a coaddition of between 500 and 1024 scans at a resolution of $0.5 \mathrm{~cm}^{-1}$. This level of resolution is critical

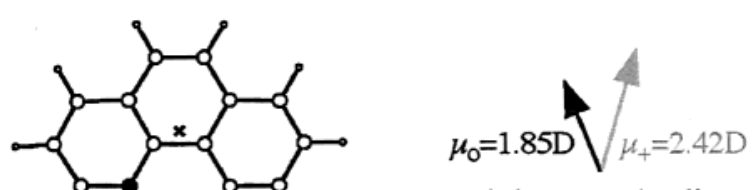

7,8-benzoquinoline
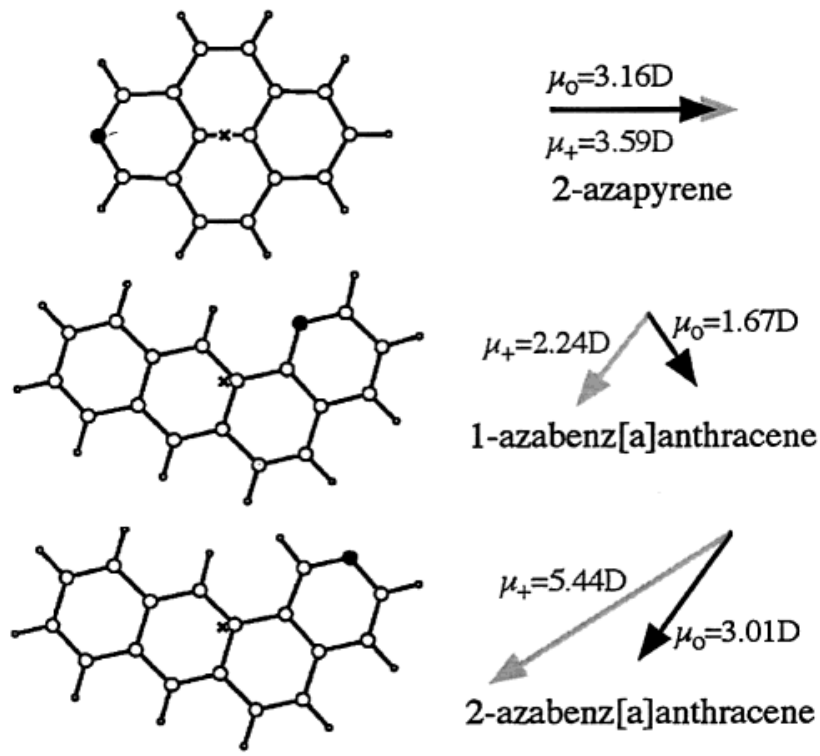

2-azabenz[a]anthracene
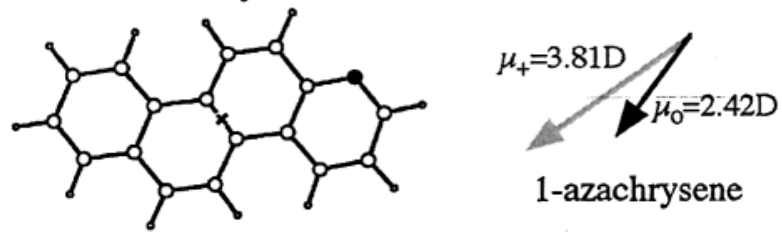

1-azachrysene
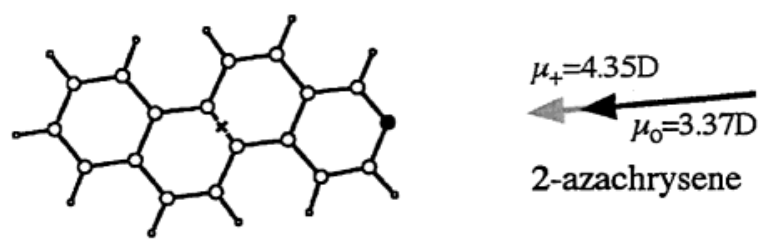

2-azachrysene
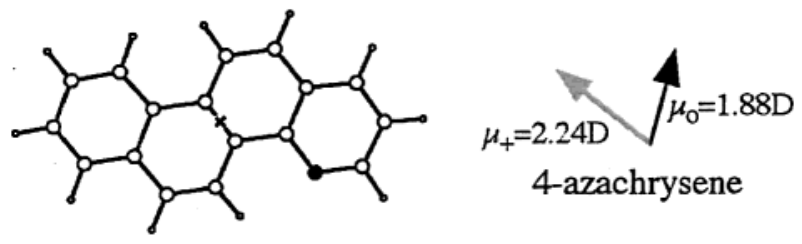

4-azachrysene

Figure 1. Structures of the PANH species considered in this study. Small open circles represent hydrogen atoms; large open circles represent carbon atoms. The large filled circle represents the nitrogen atom in each structure. The " $x$ " in each structure indicates the location of the center of mass of the molecule. The arrows to the right of each structure indicate the magnitude and orientation of the calculated dipole moment for each molecule. In each case, the black arrow represents the dipole moment of the neutral species, whereas the gray arrow represents the dipole moment of the cation. The " $a$ " rotational axis is horizontal, the " $b$ " rotational axis is vertical, and the " $c$ " rotational axis is normal to the plane of the figure.

for detecting ion bands which fall near the position of a neutral band, whereas the number of scans was chosen to optimize both the signal-to-noise as well as time requirements of each experiment. Integrated intensities $\left(\int \tau \mathrm{d} \tilde{v}\right)$ for individual bands were determined using the WIN IR Pro (Digi-Lab) spectrometer control/data analysis software package provided by Digilab. Absolute intensities $\left(A \equiv \int \tau \mathrm{d} \tilde{v} / N\right.$, where $N$ is the surface density of absorbers in molecules $/ \mathrm{cm}^{2}$ ) for the experimentally measured neutral PANH bands were determined using the theoretically 
calculated values as follows. The calculated intensities for all bands between 1600 and $500 \mathrm{~cm}^{-1}$ were summed to obtain the total absorption intensity over this region. This range was chosen to exclude the contributions of the far-infrared bands $(\tilde{v}<500$ $\mathrm{cm}^{-1}$ ) that were not measured in the experiments and those of the $\mathrm{CH}$ stretching bands which blend with overtone/combination bands in the experimental data and whose intensities are substantially overestimated by the calculations. ${ }^{3 \mathrm{a}, 8 \mathrm{e}}$ The total theoretically calculated absolute intensity was then distributed over the experimental bands on the basis of the fractional contribution of each to the total 1600 to $500 \mathrm{~cm}^{-1}$ absorption in the experimental spectrum:

$$
A_{\mathrm{i}}^{\exp }=\left[\sum_{1600 \geq \tilde{v} \geq 500} A^{\text {thy }}\right] \frac{I_{\text {rel, }, i}^{\exp }}{\sum_{1600 \geq \tilde{v} \geq 500} I_{\text {rel }}^{\exp }}
$$

This method takes advantage of the fact that, although there may be significant band-to-band variability in the accuracy of the calculated intensity, the total intensity is generally accurate to $10-20 \%$, excluding the $\mathrm{C}-\mathrm{H}$ stretching region (as illustrated in the Appendix).

PANH cations were generated by in-situ vacuum ultraviolet photolysis of the matrix isolated neutral PANH. This was accomplished with the combined $120 \mathrm{~nm}$ Lyman $\alpha(10.1 \mathrm{eV})$ and the $160 \mathrm{~nm}$ molecular hydrogen emission bands (centered around $7.8 \mathrm{eV}$ ) from a microwave-powered flowing $\mathrm{H}_{2}$ discharge lamp at a dynamic pressure of 150 mTorr. Comparison of the pre-photolysis neutral spectrum to that measured after photolysis permitted identification of PANH ion features. ${ }^{8 \mathrm{~h}}$ To confirm the attribution of a photoproduct band to a particular PANH cation, parallel experiments were conducted in which the argon matrix was doped with an electron acceptor, $\mathrm{NO}_{2}$ and in some instances $\mathrm{CCl}_{4}$, at a concentration of approximately 1 part in 1200. The presence of this electron acceptor quenches the formation of PANH anions and enhances the production of cations. For a particular photoproduct band to be assigned to the PANH cation, it must grow in the presence of the electron acceptor and do so in fixed proportion to the other bands attributed to the cation.

Assuming that all neutral PANHs which disappear upon photolysis are converted into cations, we can derive an upper limit to the ionization efficiency by measuring the percent decrease in the integrated areas of the neutral bands that accompany photolysis. The upper limits for the spectra reported here were 7,8-benzoquinoline, $11 \%$ (in the presence of $\mathrm{NO}_{2}$ ); 2-azapyrene, 11\%; 1-azabenz [a]anthracene, 3\%; 2-azabenz[a]anthracene, $10 \%$; 1-azachrysene, $7 \%$; 2-azachrysene, $13 \%$; and 4-azachrysene, $5 \%$. Because of experimental difficulties, the results reported for 7,8-benzoquinoline are those of an $\mathrm{Ar} / \mathrm{NO}_{2}$ electron acceptor experiment instead of the typical neat $\mathrm{Ar}$ experiment. No significant anion formation was observed in any of the compounds discussed in this publication. For presentation purposes, data in the cation figures was obtained by subtracting off the remaining fraction of the neutral bands, using the WinIR software package (Digi-Lab). No further data reduction was necessary.

B. Theoretical. For the species treated here, the geometries are optimized and the harmonic frequencies computed using density functional theory (DFT). Specifically, the hybrid B 3 LYP $^{12,13}$ functional was utilized in conjunction with the 4-31G basis sets. ${ }^{14}$ Calibration calculations, ${ }^{3 \mathrm{a}}$ which have been carried out for selected systems, show that a single scale factor of 0.958 brings the B3LYP harmonic frequencies computed using the 4-31G basis set into excellent agreement with the experimental fundamental frequencies. For example, for neutral 1-azachrysene, the average absolute discrepancy is $5.4 \mathrm{~cm}^{-1}$ and the maximum error is $14.9 \mathrm{~cm}^{-1}$. Although the error can be reduced by increasing the basis set (provided the $\mathrm{C}-\mathrm{H}$ stretches are scaled separately), the B3LYP/4-31G results are of sufficient accuracy to allow a critical evaluation of experiment. The calibration calculations also show that the computed B3LYP/4-31G intensities are accurate except for $\mathrm{C}-\mathrm{H}$ stretches which are, on average, about a factor of 2 larger than those determined in the matrix studies. ${ }^{3 a, 8 e}$ Although the gas-phase data are very limited, it appears that the gas-phase intensities, across the spectrum, tend to lie between the matrix and B3LYP values. ${ }^{10,11}$ It has also been observed that when two bands of the same symmetry are close in energy, their relative intensities are sensitive to the level of theory, but the sum of their intensities is very reliable.

In contrast to their hydrocarbon counterparts, the PANHs studied here all have significant permanent dipole moments and therefore exhibit pure rotational spectra. The relevant rotational constants and dipole moments have been calculated from the Gaussian output. The B3LYP dipole moments are computed at the center of mass, with the $x, y$, and $z$ axes aligned along the principle moments of inertia. The rotational constants are computed using the equilibrium B3LYP geometry, with vibrational contributions to the geometry neglected.

All calculations were performed using the Gaussian 98 computer code. ${ }^{15}$ The net charge on each atom is determined using the Mulliken population analysis. To aid in the analysis, the vibrational modes and displacement vectors are viewed using the interactive molecular graphics tool MOLEKEL. ${ }^{16}$

\section{Results}

A. 4000-500 $\mathrm{cm}^{-1}$ Spectra of Neutral PANHs. The measured mid-infrared spectra of the argon matrix isolated PANHs considered in this study are presented according to family. Figure 2 shows the spectra of 1-, 2-, and 4-azachrysene. Figure 3 shows the spectra of 1- and 2-azabenz $[a]$ anthracene. Figures 4 and 5 show the spectra of 2 -azapyrene and 7,8benzoquinoline, respectively. The spectrum of the corresponding parent hydrocarbon of each family is included in each case for reference. The observed band positions and intensities are tabulated and compared to their theoretically calculated values grouped in analogous fashion with the azachrysenes in Table 1, the azabenz $[a]$ anthracenes in Table 2, and 7,8-benzoquinoline and 2-azapyrene in Table 3.

Close inspection of Tables 1-3 shows that, as with most PAHs previously studied, the agreement between the measured peak positions and their theoretically calculated counterparts is generally good. Most measured bands lie within $5-10 \mathrm{~cm}^{-1}$ of predicted values, some within $20 \mathrm{~cm}^{-1}$ and only a few differ by as much as $30 \mathrm{~cm}^{-1}$. However, the variation between the measured and calculated band intensities are significantly larger, with differences of factors of three or more common. Despite this, the overall agreement between theory and experiment is good, and the calculated normal modes, charge distributions, dipole moments, etc. provide valuable insight into the molecular characteristics. A detailed comparison of the experimental and theoretical results for 1 -azabenz $[a]$ anthracene can be found in the Appendix.

Because of substitution of nitrogen for a $\mathrm{C}-\mathrm{H}$ "group", besides the possibly reduced symmetry, the normal modes will be more or less influenced by the appearance of $\mathrm{CN}$-stretching and $\mathrm{CNC}$-bending motions and therefore yield shifts in intensity 


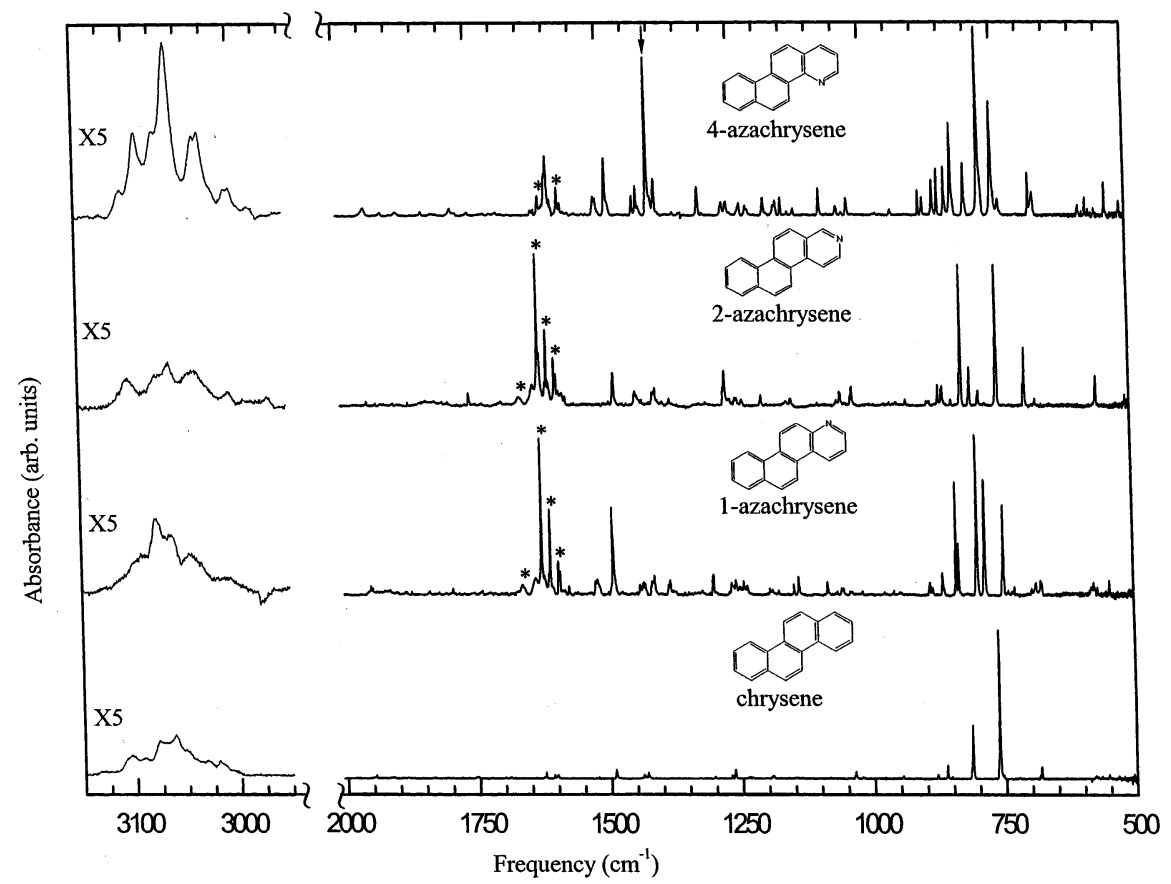

Figure 2. Mid-infrared spectra of 1-, 2-, and 4-azachrysene isolated in an argon matrix. The spectrum of the parent hydrocarbon, chrysene, is shown for reference. All matrixes were deposited and studied at $14 \mathrm{~K}$. The argon to PANH/PAH ratio was in excess of 1200/1. The arrow indicates the $1400 \mathrm{~cm}^{-1}$ feature discussed in section III.A. An asterisk (*) indicates the position of a contaminant band (primarily $\mathrm{H}_{2} \mathrm{O}$ ).

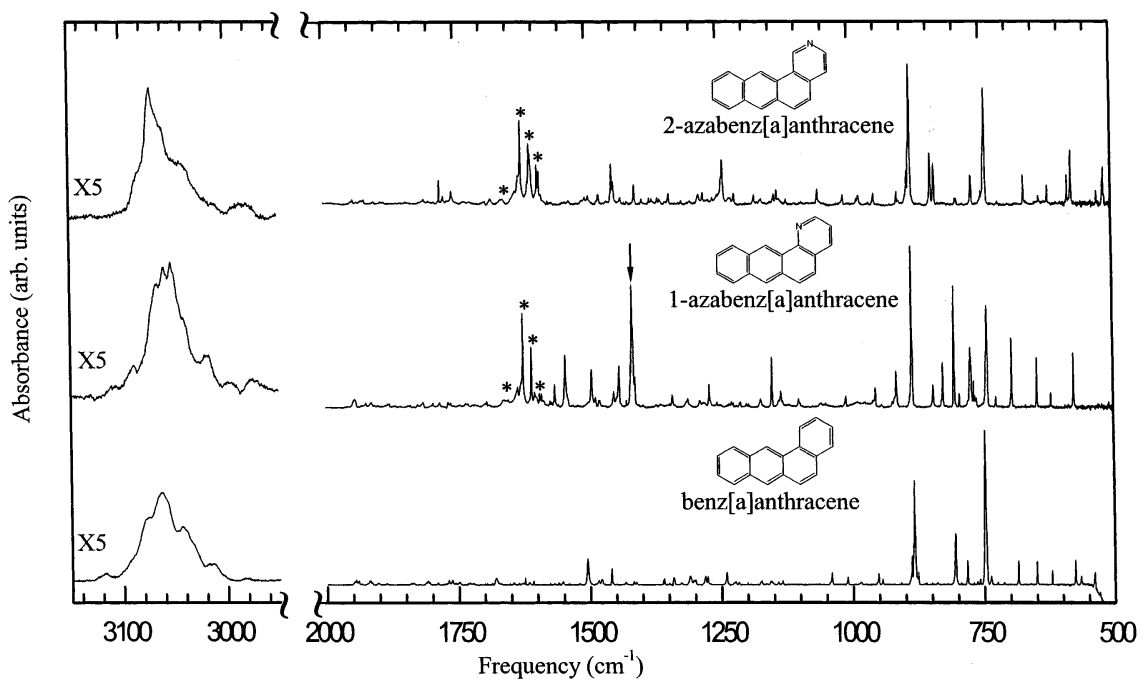

Figure 3. Mid-infrared spectra of 1- and 2-azabenz $[a]$ anthracene isolated in an argon matrix. The spectrum of the parent hydrocarbon, benz $[a]-$ anthracene, is shown for reference. All matrixes were deposited and studied at $14 \mathrm{~K}$. The argon to PANH/PAH ratio was in excess of $1200 / 1$. The arrow indicates the $1400 \mathrm{~cm}^{-1}$ feature discussed in section III.A. An asterisk (*) indicates the position of a contaminant band (primarily $\mathrm{H}_{2} \mathrm{O}$ ).

and position of the observed spectral bands compared to "corresponding" modes in the parent molecule. Inspection of Figures 2-5 shows that, in the neutral species, nitrogen substitution is not accompanied by the appearance of any prominent bands in regions of the spectrum that would clearly distinguish them from the modes of the parent aromatic hydrocarbons. Consequently, it is not possible to distinguish the nitrogen-dominated vibrational modes of PANHs on the basis of the experimental data alone. Turning to theoretical data, decomposition of the individual atomic displacements of the calculated vibrations reveals that modes dominated by $\mathrm{CN}$ stretching and CNC in-plane bending tend to fall in the 1100$1000 \mathrm{~cm}^{-1}$ region. Indeed, close inspection of Figures $2-5$ does reveal a general increase in infrared activity in this region for the PANHs compared to their parent PAH. These modes are, however, weak to very weak $\left(I_{\text {rel }} \lesssim 0.1\right)$ and are not even included in Tables $1-3$. This is consistent with the failure of these modes to produce a notable impact on the appearance of the observed spectra. The out-of-plane CNC warping modes make their greatest contributions to the lowest frequency modes of the molecule. Although many of these fall in the far-infrared region of the spectrum, several modes in the $600-500 \mathrm{~cm}^{-1}$ region have been found to carry significant CNC out-of-plane warping character as well.

Despite the global similarity between the spectra of the neutral PANHs and those of their parent PAHs, there are two aspects of the spectra shown in Figures 2-5 that set the spectra of nitrogen-bearing aromatics apart. First, inspection of these figures shows that nitrogen addition induces a pronounced, global enhancement of the features in the region between 1650 and $1100 \mathrm{~cm}^{-1}$, reminiscent of the spectral change that accompanies ionization..$^{\mathrm{a}, 8 \mathrm{a}}$ This behavior is quantified in Table 4 which shows the integrated intensity across the 1600-1100 $\mathrm{cm}^{-1}$ region, as well as the integrated intensities across the 


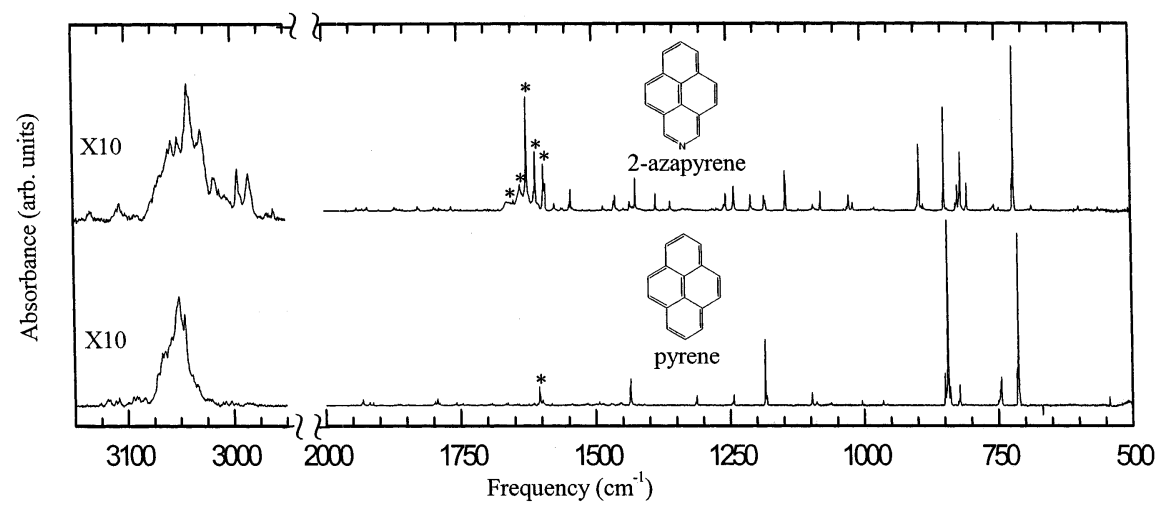

Figure 4. Mid-infrared spectrum of 2-azapyrene isolated in an argon matrix. The spectrum of the parent hydrocarbon, pyrene, is shown for reference. All matrixes were deposited and studied at $14 \mathrm{~K}$. The argon to PANH/PAH ratio was in excess of 1200/1. An asterisk (*) indicates the position of a contaminant band (primarily $\mathrm{H}_{2} \mathrm{O}$ ).

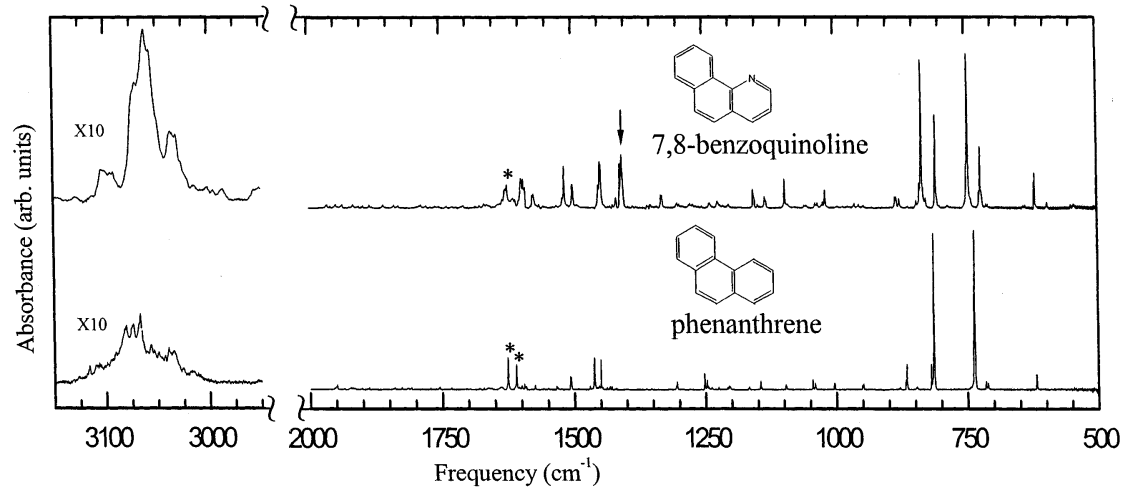

Figure 5. Mid-infrared spectrum of 7,8-benzoquinoline isolated in an argon matrix. The spectrum of the parent hydrocarbon, phenanthrene, is shown for reference. All matrixes were deposited and measured at $14 \mathrm{~K}$. The argon to PANH/PAH ratio was in excess of 1200/1. The arrow indicates the $1400 \mathrm{~cm}^{-1}$ feature discussed in ssection III.A. An asterisk (*) indicates the position of a contaminant band (primarily $\mathrm{H}_{2} \mathrm{O}$ ).

$1100-500$ and $3100-3000 \mathrm{~cm}^{-1}$ regions, for each of the species in Figures $2-5$. The modes that fall in the $1600-1100 \mathrm{~cm}^{-1}$ region correspond to the aromatic $\mathrm{CC}$ and $\mathrm{CN}$ stretching and $\mathrm{CH}$ in-plane bending vibrations. For the PANH species, the total absorption intensity is twice that of the corresponding PAH. For 2-azapyrene ( $C_{2 v}$ symmetry), 7,8-benzoquinoline, and the three azachrysenes (all $C_{\mathrm{s}}$ symmetry) this may, in part, be due to a general increase in the number of infrared active modes resulting from the lower symmetry of the PANH species compared to the parent PAHs (pyrene, $D_{2 h}$; phenanthrene, $C_{2 v}$, chrysene, $C_{2 h}$ ). However, this effect is also observed in the azabenz $[a]$ anthracenes $\left(C_{\mathrm{s}}\right.$ symmetry) which share the same symmetry as their parent PAH, so this effect cannot be solely attributed to lowering of the molecular symmetry.

Table 4 also shows that, for the neutral species, nitrogen insertion does not substantially alter the total absorption intensity of the $\mathrm{CH}$ out-of-plane bending and skeletal deformation modes in the $1100-500 \mathrm{~cm}^{-1}$ region. However, the $\mathrm{CH}$ stretching modes in the $3100-3000 \mathrm{~cm}^{-1}$ are mildly suppressed by approximately $25 \%$. These effects are also similar to that found to accompany ionization, although the enhancement of the $\mathrm{CC}$ stretching/CH in-plane bending modes and the suppression of the $\mathrm{CH}$ stretching modes is more modest than that which accompanies ionization. Together, these observations suggest that substitution of the electronegative nitrogen atom in the aromatic network of the PANHs produces a pseudo-ionization effect. Indeed, this hypothesis is supported by an analysis of the average Mulliken populations on the carbon atoms of the PANHs and their parent PAHs listed in Table 5. In all cases, nitrogen insertion modifies the average charge on each carbon atom to the point that it more closely resembles the charge on

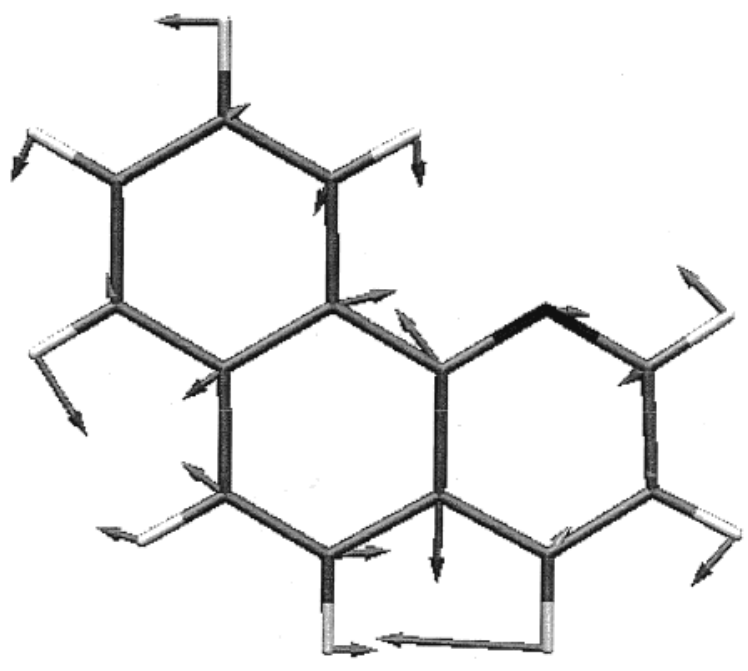

Figure 6. Relative atomic displacements contributing to the nominal "1400 $\mathrm{cm}^{-1}$ " vibrational mode in 7,8-benzoquinoline.

the carbon atoms of the parent $\mathrm{PAH}$ cation than that of the parent neutral PAH. Hence, the observed pseudo-cationic nature of the mid-infrared spectra.

The second unique influence of nitrogen substitution on the infrared spectra of neutral PANHs is the appearance of a prominent band near $1400 \mathrm{~cm}^{-1}$ for 1 -azabenz[a]anthracene, 4-azachrysene, and 7,8-benzoquinoline. This feature is marked with an arrow in Figures 2, 3, and 5. In each of the species showing this feature, the nitrogen is para to a $\mathrm{CH}$ group. The vibrational motion that gives rise to this uncharacteristically strong feature is illustrated for 7,8-benzoquinoline in Figure 6. 
TABLE 1: Theoretical and Experimental Band Positions and Intensities for the Neutral Azachrysenes ${ }^{a}$

\begin{tabular}{|c|c|c|c|c|c|c|c|c|c|c|c|c|c|c|c|c|c|c|c|c|}
\hline \multicolumn{7}{|c|}{ 1-azachrysene } & \multicolumn{7}{|c|}{ 2-azachrysene } & \multicolumn{7}{|c|}{ 4-azachrysene } \\
\hline \multicolumn{4}{|c|}{ theory } & \multicolumn{3}{|c|}{ experiment } & \multicolumn{4}{|c|}{ theory } & \multicolumn{3}{|c|}{ experiment } & \multicolumn{4}{|c|}{ theory } & \multicolumn{3}{|c|}{ experiment } \\
\hline $\begin{array}{c}\tilde{v} \\
\left(\mathrm{~cm}^{-1}\right)\end{array}$ & $\begin{array}{c}A \\
\mathrm{~km} / \mathrm{mol}\end{array}$ & $I_{\mathrm{rel}}$ & $\Gamma$ & $\begin{array}{c}\tilde{v} \\
\left(\mathrm{~cm}^{-1}\right)\end{array}$ & $\begin{array}{c}A \\
\mathrm{~km} / \mathrm{mol}\end{array}$ & $I_{\mathrm{rel}}$ & $\begin{array}{c}\tilde{v} \\
\left(\mathrm{~cm}^{-1}\right)\end{array}$ & $\begin{array}{c}A \\
\mathrm{~km} / \mathrm{mol}\end{array}$ & $I_{\text {rel }}$ & $\Gamma$ & $\begin{array}{c}\tilde{v} \\
\left(\mathrm{~cm}^{-1}\right)\end{array}$ & $\begin{array}{c}A \\
\mathrm{~km} / \mathrm{mol}\end{array}$ & $I_{\text {rel }}$ & $\begin{array}{c}\tilde{v} \\
\left(\mathrm{~cm}^{-1}\right)\end{array}$ & $\begin{array}{c}A \\
\mathrm{~km} / \mathrm{mol}\end{array}$ & $I_{\mathrm{rel}}$ & $\Gamma$ & $\begin{array}{c}\tilde{v} \\
\left(\mathrm{~cm}^{-1}\right)\end{array}$ & $\begin{array}{c}A \\
\mathrm{~km} / \mathrm{mol}\end{array}$ & $I_{\text {rel }}$ \\
\hline 234.1 & 7.1 & 0.114 & $\mathrm{~A}^{\prime \prime}$ & & & & 423.4 & 6.1 & 0.095 & $A^{\prime \prime}$ & & & & 240.2 & 5.5 & 0.106 & $\mathrm{~A}^{\prime \prime}$ & & & \\
\hline 477.8 & 12.7 & 0.203 & $\mathrm{~A}^{\prime}$ & & & & 564.1 & 6.5 & 0.101 & $A^{\prime \prime}$ & 563.3 & 11.5 & 0.18 & 491.0 & 7.3 & 0.142 & $\mathrm{~A}^{\prime}$ & & & \\
\hline 576.9 & 0.6 & 0.010 & $\mathrm{~A}^{\prime}$ & 576.2 & 8.3 & 0.19 & 565.2 & 3.2 & 0.051 & $\mathrm{~A}^{\prime}$ & & & & 672.6 & 3.3 & 0.064 & $\mathrm{~A}^{\prime}$ & 675.4 & 6.6 & 0.16 \\
\hline 584.1 & 5.7 & 0.092 & $A^{\prime \prime}$ & & & & 699.9 & 18.7 & 0.292 & $\mathrm{~A}^{\prime}$ & $699.6 *$ & 23.1 & 0.37 & 683.8 & 8.2 & 0.159 & $\mathrm{~A}^{\prime}$ & 683.0 & 5.0 & 0.12 \\
\hline 671.7 & 3.1 & 0.050 & $\mathrm{~A}^{\prime}$ & $\begin{array}{l}674.9 \\
677.1\end{array}$ & 5.2 & 0.12 & 754.1 & 55.1 & 0.864 & $A^{\prime \prime}$ & 752.3 & 62.6 & 1.00 & 755.3 & 27.0 & 0.525 & $\mathrm{~A}^{\prime \prime}$ & 753.2 & 26.7 & 0.64 \\
\hline 682.6 & 1.4 & 0.023 & $A^{\prime \prime}$ & & & & 786.0 & 6.1 & 0.096 & $A^{\prime \prime}$ & 787.6 & 5.6 & 0.09 & 781.5 & 51.5 & 1.000 & $\mathrm{~A}^{\prime \prime}$ & 778.0 & 41.6 & 1.00 \\
\hline 751.4 & 20.7 & 0.331 & $\mathrm{~A}^{\prime \prime}$ & 747.5 & 23.5 & 0.54 & 806.3 & 6.0 & 0.095 & $\mathrm{~A}^{\prime \prime}$ & 804.3 & 14.8 & 0.24 & 815.5 & 36.6 & 0.710 & $A^{\prime \prime}$ & 805.9 & 9.9 & 0.24 \\
\hline 783.3 & 27.8 & 0.445 & $\mathrm{~A}^{\prime \prime}$ & $782.4^{*}$ & 35.6 & 0.82 & 825.6 & 63.8 & 1.000 & $A^{\prime \prime}$ & $819.9^{*}$ & 55.0 & 0.88 & 837.2 & 18.9 & 0.366 & $A^{\prime \prime}$ & 830.2 & 17.6 & 0.42 \\
\hline 801.8 & 62.5 & 1.000 & $\mathrm{~A}^{\prime \prime}$ & $797.1 *$ & 43.7 & 1.0 & 840.7 & 7.1 & 0.111 & $\mathrm{~A}^{\prime \prime}$ & 839.9 & 1.3 & 0.02 & 851.4 & 7.3 & 0.141 & $\mathrm{~A}^{\prime}$ & 843.4 & 6.2 & 0.15 \\
\hline 837.2 & 12.0 & 0.192 & $\mathrm{~A}^{\prime \prime}$ & 832.7 & 8.5 & 0.19 & 848.8 & 9.2 & 0.144 & $A^{\prime}$ & $\begin{array}{l}856.3 \\
857.8\end{array}$ & 8.2 & 0.13 & 861.9 & 7.7 & 0.150 & $\mathrm{~A}^{\prime \prime}$ & 856.8 & 4.7 & 0.11 \\
\hline 847.8 & 22.9 & 0.367 & $A^{\prime \prime}$ & $837.4 *$ & 19.3 & 0.44 & 867.8 & 6.4 & 0.100 & $A^{\prime \prime}$ & 864.3 & 5.6 & 0.09 & 871.6 & 12.2 & 0.238 & $\mathrm{~A}^{\prime \prime}$ & 866.0 & 5.5 & 0.13 \\
\hline 855.8 & 2.2 & 0.035 & $\mathrm{~A}^{\prime}$ & $863.8 *$ & 7.0 & 0.16 & 1020.1 & 10.6 & 0.167 & $\mathrm{~A}^{\prime}$ & $1028.3^{*}$ & 10.9 & 0.17 & 1072.2 & 3.6 & 0.069 & $\mathrm{~A}^{\prime}$ & 1081.4 & 4.0 & 0.10 \\
\hline 867.4 & 4.6 & 0.073 & $\mathrm{~A}^{\prime \prime}$ & & & & 1030.1 & 1.9 & 0.030 & $\mathrm{~A}^{\prime}$ & & & & 1163.6 & 7.5 & 0.146 & $A^{\prime}$ & 1153.9 & 2.3 & 0.06 \\
\hline 875.9 & 1.2 & 0.018 & $\mathrm{~A}^{\prime}$ & & & & 1043.4 & 0.6 & 0.009 & $\mathrm{~A}^{\prime}$ & $\begin{array}{l}1049.8 \\
1051.3\end{array}$ & 6.6 & 0.11 & 1176.9 & 1.8 & 0.035 & $\mathrm{~A}^{\prime}$ & $\begin{array}{l}1163.8 \\
1167.7\end{array}$ & 4.8 & 0.12 \\
\hline 1139.8 & 1.9 & 0.030 & $\mathrm{~A}^{\prime}$ & 1136.7 & 4.5 & 0.10 & 1264.5 & 19.9 & 0.312 & $\mathrm{~A}^{\prime}$ & $1268.9^{*}$ & 26.0 & 0.42 & 1190.4 & 3.3 & 0.064 & $\mathrm{~A}^{\prime}$ & 1186.9 & 4.0 & 0.10 \\
\hline 1227.7 & 0.3 & 0.005 & $\mathrm{~A}^{\prime}$ & 1233.6 & 5.1 & 0.12 & 1384.2 & 8.2 & 0.128 & $\mathrm{~A}^{\prime}$ & $1401.8^{*}$ & 15.8 & 0.25 & 1266.1 & 9.1 & 0.177 & $\mathrm{~A}^{\prime}$ & 1257.4 & 4.2 & 0.10 \\
\hline 1237.3 & 3.4 & 0.055 & $\mathrm{~A}^{\prime}$ & 1240.7 & 5.5 & 0.13 & 1428.6 & 10.3 & 0.161 & $\mathrm{~A}^{\prime}$ & 1439.8 & 13.8 & 0.22 & & & & & 1266.0 & 3.1 & 0.07 \\
\hline 1247.2 & 2.4 & 0.038 & $A^{\prime}$ & 1248.2 & 4.5 & 0.10 & 1434.5 & 3.1 & 0.049 & $\mathrm{~A}^{\prime}$ & & & & 1307.2 & 3.4 & 0.065 & $\mathrm{~A}^{\prime}$ & 1311.8 & 5.8 & 0.14 \\
\hline & & & & 1255.5 & 6.4 & 0.15 & 1471.4 & 24.1 & 0.377 & $\mathrm{~A}^{\prime}$ & 1480.7 & 17.8 & 0.28 & 1375.7 & 13.4 & 0.261 & $\mathrm{~A}^{\prime}$ & 1394.3 & 9.2 & 0.22 \\
\hline 1259.4 & 11.2 & 0.179 & $\mathrm{~A}^{\prime}$ & 1263.8 & 7.0 & 0.16 & 1547.6 & 6.1 & 0.096 & $A^{\prime}$ & 1572.9 & 2.6 & 0.04 & 1393.3 & 36.3 & 0.704 & $\mathrm{~A}^{\prime}$ & 1408.0 & 31.9 & 0.77 \\
\hline 1293.6 & 3.9 & 0.062 & $A^{\prime}$ & $1297.7^{*}$ & 8.3 & 0.19 & 1562.5 & 27.5 & 0.431 & $\mathrm{~A}^{\prime}$ & 1579.8 & 10.2 & 0.16 & 1427.3 & 5.2 & 0.100 & $\mathrm{~A}^{\prime}$ & $1428.9^{*}$ & 6.9 & 0.17 \\
\hline 1351.8 & 9.6 & 0.154 & $\mathrm{~A}^{\prime}$ & $1380.2^{*}$ & 5.9 & 0.14 & 1589.2 & 17.8 & 0.278 & $\mathrm{~A}^{\prime}$ & 1586.4 & 7.6 & 0.12 & 1480.0 & 12.3 & 0.238 & $\mathrm{~A}^{\prime}$ & 1487.6 & 14.0 & 0.34 \\
\hline 1400.0 & 14.6 & 0.233 & $\mathrm{~A}^{\prime}$ & 1410.3 & 12.9 & 0.30 & 1603.0 & 5.9 & 0.092 & $\mathrm{~A}^{\prime}$ & 1604.4 & 9.9 & 0.16 & 1490.5 & 11.6 & 0.226 & $\mathrm{~A}^{\prime}$ & $\begin{array}{l}1506.5 \\
1510.0\end{array}$ & 7.8 & 0.19 \\
\hline 1418.9 & 7.1 & 0.114 & $\mathrm{~A}^{\prime}$ & $1430.5^{*}$ & 8 & 0.19 & & & & & & & & 1542 & 7.3 & 0.141 & $A^{\prime}$ & 1532.4 & 0.3 & 0.01 \\
\hline 1434.9 & 3.9 & 0.062 & $\mathrm{~A}^{\prime}$ & 1438.1 & 4.5 & 0.10 & & & & & & & & 1580.2 & 14.2 & 0.275 & $\mathrm{~A}^{\prime}$ & 1579.1 & 4.0 & 0.10 \\
\hline 1478.6 & 30.3 & 0.485 & $\mathrm{~A}^{\prime}$ & 1489.4 & 34.4 & 0.79 & & & & & & & & 1585.3 & 18.3 & 0.355 & $A^{\prime}$ & 1599.4 & 23.0 & 0.55 \\
\hline 1504.7 & 9.2 & 0.148 & $A^{\prime}$ & $1518.7^{*}$ & 14.4 & 0.33 & & & & & & & & & & & & & & \\
\hline 1518.3 & 1.5 & 0.024 & $\mathrm{~A}^{\prime}$ & & & & & & & & & & & & & & & & & \\
\hline 1568.0 & 10.9 & 0.174 & $\mathrm{~A}^{\prime}$ & 1580.4 & 0.8 & 0.02 & & & & & & & & & & & & & & \\
\hline \multicolumn{4}{|c|}{$\begin{array}{l}3050.9,3051.5,3059.0 \\
3073.0,3075.1,3081.3 \\
3086.2,3099.4^{*}, 3105.9\end{array}$} & \multicolumn{3}{|c|}{$\begin{array}{l}3045.4,3065.7 \\
3077.5^{*}, 3093.8\end{array}$} & \multicolumn{4}{|c|}{$\begin{array}{l}3036.5,3053.2,3054.9 \\
3060.0,3068.5,3076.5 \\
3087.0,3102.3,3104.1\end{array}$} & \multicolumn{3}{|c|}{$\begin{array}{c}2968,3005,3037^{*} \\
3062^{*}, 3103^{*}\end{array}$} & $\begin{array}{l}3049 . \\
3056 . \\
3083 .\end{array}$ & $\begin{array}{r}.3,3050.5 \\
.5,3057.8 \\
4,3086.0 \\
3107.3\end{array}$ & $\begin{array}{l}3052.3 \\
3073 . \\
3098 .\end{array}$ & & \multicolumn{3}{|c|}{$\begin{array}{c}3003,3030,3034,3060^{*}, \\
3072,3090,3105\end{array}$} \\
\hline
\end{tabular}

SUM $\quad 196.7 \quad 3.15 \quad A^{\prime} \quad$ SUM

${ }^{a}$ Data truncated at the $10 \%$ relative intensity level. The complete, untruncated tables are available electronically at www.astrochemistry.org/ pahdata/index.html. The * indicates the strongest member(s) of a multiplet.

The mode is dominated by a rocking of the CNC moiety combined with a exaggerated in-plane wagging of the para $\mathrm{CH}$ group. Only one of the molecules considered in this study, 1-azachrysene, shares this structural characteristic but does not show an intense feature in the vicinity of $1400 \mathrm{~cm}^{-1}$. Analysis of the atomic displacements for this mode in the Gaussian output shows that in this molecule the $\mathrm{CH}$ in-plane motions are outof-phase with the para $\mathrm{CH}$ wagging, effectively quenching the intensity of the mode.

B. 4000-500 $\mathrm{cm}^{-1}$ Spectra of PANH Cations. The spectra of the argon matrix isolated 1-azachrysene, 2-azachrysene, and 4-azachrysene cations are compared to that of the parent chrysene cation in Figure 7. Likewise, the spectra of the 1 -azabenz $[a]$ anthracene and 2-azabenz $[a]$ anthrecene cations are compared to the benz[a]anthracene cation in Figure 8; the spectrum of the 2-azapyrene cation is compared to that of the pyrene cation in Figure 9; and the spectrum of the 7,8benzoquinoline cation is compared to that of the phenanthrene cation in Figure 10. The observed band positions and relative intensities of the azachrysene cations, the azabenz $[a]$ anthracene cations, the 2-azapyrene cation, and the 7,8-benzoquinoline cation are tabulated and compared to their theoretically calculated values in Tables 6, 7, and 8, respectively. For the ions, because of uncertainties in establishing ion concentration and charge effects within the matrix, only relative band intensities are reported for the experiments.

Inspection of Tables $6-8$ reveals frequency discrepancies between theory and experiment that are somewhat higher than for the neutral species described above. For the cations, although the positional agreement between theory and experiment is similar to or only slightly poorer than that observed for the neutral species, more striking is the substantially larger number of bands predicted by theory than are observed in the experimental data. The most probable explanation for the lower-thanexpected number of observed cation bands is the pseudoionization effect discussed in the previous section. Given that neutral PANH molecules exhibit some of the spectroscopic character of ionized species, it is likely that the average band position shift induced by ionization is less than that observed for the aromatic hydrocarbon cations studied previously. Because photolysis of a neutral sample even under the best of conditions converts only ca. $10 \%$ of the precursor neutral species into cations, screening of cation bands by residual neutral bands in the post-photolysis spectra represents a relatively greater problem for the PANH species considered here. For example, consider the $\mathrm{CH}$ out-of-plane bending features of the 4-azachry- 
TABLE 2: Theoretical and Experimental Band Positions and Intensities for the Neutral Azabenz $[a]$ anthracenes ${ }^{a}$

\begin{tabular}{|c|c|c|c|c|c|c|c|c|c|c|c|c|c|}
\hline \multicolumn{7}{|c|}{ 1-azabenz $[a]$ anthracene } & \multicolumn{7}{|c|}{ 2-azabenz $[a]$ anthracene } \\
\hline \multicolumn{4}{|c|}{ theory } & \multicolumn{3}{|c|}{ experiment } & \multicolumn{4}{|c|}{ theory } & \multicolumn{3}{|c|}{ experiment } \\
\hline $\begin{array}{c}\tilde{v} \\
\left(\mathrm{~cm}^{-1}\right)\end{array}$ & $\begin{array}{c}A \\
\mathrm{~km} / \mathrm{mol}\end{array}$ & $I_{\text {rel }}$ & $\Gamma$ & $\begin{array}{c}\tilde{v} \\
\left(\mathrm{~cm}^{-1}\right)\end{array}$ & $\begin{array}{c}A \\
\mathrm{~km} / \mathrm{mol}\end{array}$ & $I_{\text {rel }}$ & $\begin{array}{c}\tilde{v} \\
\left(\mathrm{~cm}^{-1}\right)\end{array}$ & $\begin{array}{c}A \\
\mathrm{~km} / \mathrm{mol}\end{array}$ & $I_{\text {rel }}$ & $\Gamma$ & $\begin{array}{c}\tilde{v} \\
\left(\mathrm{~cm}^{-1}\right)\end{array}$ & $\begin{array}{c}A \\
\mathrm{~km} / \mathrm{mol}\end{array}$ & $I_{\text {rel }}$ \\
\hline 477.0 & 11.6 & 0.222 & $\mathrm{~A}^{\prime \prime}$ & & & & 469.1 & 11.3 & 0.172 & $\mathrm{~A}^{\prime \prime}$ & & & \\
\hline 579.6 & 7.3 & 0.139 & $\mathrm{~A}^{\prime}$ & 576.3 & 8.6 & 0.16 & 519.3 & 6.7 & 0.103 & $\mathrm{~A}^{\prime \prime}$ & 513.9 & 10.4 & 0.15 \\
\hline 649.9 & 4.2 & 0.080 & $\mathrm{~A}^{\prime}$ & 646.3 & 6.9 & 0.13 & 582.4 & 9.5 & 0.144 & $\mathrm{~A}^{\prime \prime}$ & 576.1 & 11.4 & 0.17 \\
\hline 701.6 & 10.1 & 0.194 & $A^{\prime \prime}$ & 694.4 & 11.3 & 0.21 & 744.2 & 40.5 & 0.616 & $A^{\prime \prime}$ & $741.3 *$ & 49.6 & 0.74 \\
\hline 745.4 & 32.3 & 0.618 & $A^{\prime \prime}$ & 741.4 & 34.1 & 0.63 & 759.2 & 7.9 & 0.120 & $\mathrm{~A}^{\prime}$ & 767.9 & 8.1 & 0.12 \\
\hline 776.3 & 20.5 & 0.392 & $\mathrm{~A}^{\prime \prime}$ & 773.2 & 21.6 & 0.40 & 845.0 & 12.7 & 0.194 & $\mathrm{~A}^{\prime \prime}$ & 838.3 & 12.2 & 0.18 \\
\hline 816.7 & 30.6 & 0.585 & $A^{\prime \prime}$ & 804.0 & 23.7 & 0.44 & 852.1 & 13.2 & 0.201 & $\mathrm{~A}^{\prime \prime}$ & 845.1 & 15.9 & 0.24 \\
\hline 847.4 & 3.4 & 0.064 & $A^{\prime \prime}$ & 825.8 & 9.0 & 0.17 & 874.5 & 2.3 & 0.035 & $\mathrm{~A}^{\prime}$ & $883.7 *$ & 67.3 & 1.00 \\
\hline 874.6 & 5.8 & 0.110 & $\mathrm{~A}^{\prime}$ & & & & 889.0 & 65.7 & 1.000 & $\mathrm{~A}^{\prime \prime}$ & & & \\
\hline 895.0 & 42.7 & 0.817 & $\mathrm{~A}^{\prime \prime}$ & 884.4 & 41.6 & 0.77 & 1221.4 & 8.3 & 0.126 & $\mathrm{~A}^{\prime}$ & 1226.1 & 2.4 & 0.04 \\
\hline 937.2 & 1.6 & 0.031 & $A^{\prime \prime}$ & 914.3 & 13.2 & 0.24 & 1239.2 & 14.7 & 0.224 & $\mathrm{~A}^{\prime}$ & $1239.7^{*}$ & 25.8 & 0.38 \\
\hline 962.8 & 10.6 & 0.202 & $\mathrm{~A}^{\prime \prime}$ & 954.1 & 5.6 & 0.10 & 1431.1 & 12.6 & 0.192 & $\mathrm{~A}^{\prime}$ & 1434.2 & 1.8 & 0.03 \\
\hline 1154.5 & 5.2 & 0.100 & $\mathrm{~A}^{\prime}$ & 1133.6 & 7.4 & 0.14 & 1446.3 & 7.3 & 0.111 & $\mathrm{~A}^{\prime}$ & $1447.7,1451.0$ & 16.5 & 0.24 \\
\hline 1164.2 & 10.4 & 0.200 & $\mathrm{~A}^{\prime}$ & 1150.3 & 10.3 & 0.19 & 1480.8 & 7.7 & 0.117 & $\mathrm{~A}^{\prime}$ & 1496.1 & 2.2 & 0.03 \\
\hline 1273.8 & 6.4 & 0.122 & $\mathrm{~A}^{\prime}$ & 1269.6 & 5.3 & 0.10 & 1565.8 & 31.0 & 0.472 & $A^{\prime}$ & 1586.4 & 1.6 & 0.02 \\
\hline 1284.1 & 5.3 & 0.102 & $\mathrm{~A}^{\prime}$ & 1287.4 & 2.6 & 0.05 & 1588.5 & 6.3 & 0.096 & $A^{\prime}$ & & & \\
\hline 1305.4 & 2.3 & 0.043 & $\mathrm{~A}^{\prime}$ & 1310.5 & 5.2 & 0.10 & 1609.8 & 3.8 & 0.058 & $\mathrm{~A}^{\prime}$ & $1606.0^{*}$ & 20.3 & $0.3^{b}$ \\
\hline 1396.6 & 52.3 & 1.000 & $\mathrm{~A}^{\prime}$ & 1415.9 & 54.2 & 1.00 & 1617.1 & 6.4 & 0.097 & $\mathrm{~A}^{\prime}$ & & & \\
\hline 1414.3 & 1.1 & 0.021 & $\mathrm{~A}^{\prime}$ & & & & & & & & & & \\
\hline 1432.9 & 17.0 & 0.324 & $\mathrm{~A}^{\prime}$ & 1440.9 & 14.7 & 0.27 & & & & & & & \\
\hline 1444.0 & 1.2 & 0.023 & $\mathrm{~A}^{\prime}$ & 1451.2 & 5.3 & 0.10 & & & & & & & \\
\hline 1481.7 & 14.1 & 0.269 & $\mathrm{~A}^{\prime}$ & 1493.5 & 10.7 & 0.20 & & & & & & & \\
\hline 1518.5 & 22.0 & 0.421 & $\mathrm{~A}^{\prime}$ & 1543.4 & 21.6 & 0.40 & & & & & & & \\
\hline 1567.3 & 9.1 & 0.174 & $\mathrm{~A}^{\prime}$ & 1563.8 & 6.0 & 0.11 & & & & & & & \\
\hline 1610.0 & 7.5 & 0.143 & $\mathrm{~A}^{\prime}$ & 1601.7 & 4.4 & 0.08 & & & & & & & \\
\hline
\end{tabular}

3046.7, 3051.9, 3056.2, 3065.3, 2995, 3018, 3052* $3065.6,3079.8,3086.9$
$3059^{*}, 3067 *, 3089$
3048.0, 3062.6, 3066.3, 3068.6, $3077.5,3081.0,3082.1$
$2984,3072 *$

$207.7 \quad 3.16 \quad \mathrm{~A}^{\prime} \quad$ SUM
$86.0 \quad 1.28$

${ }^{a}$ Data truncated at the $10 \%$ relative intensity level. The complete, untruncated tables are available electronically at www.astrochemistry.org/ pahdata/index.html. The * indicates strongest member of a multiplet. ${ }^{b}$ Area uncertain because of overlap with band of argon matrix isolated $\mathrm{H}_{2} \mathrm{O}$.

TABLE 3: Theoretical and Experimental Band Positions and Intensities for Neutral 7,8-Benzoquinoline and 2-Azapyrene ${ }^{a}$

\begin{tabular}{|c|c|c|c|c|c|c|c|c|c|c|c|c|c|}
\hline \multicolumn{7}{|c|}{ 7,8-benzoquinoline } & \multicolumn{7}{|c|}{ 2-azapyrene } \\
\hline \multicolumn{4}{|c|}{ theory } & \multicolumn{3}{|c|}{ experiment } & \multicolumn{4}{|c|}{ theory } & \multicolumn{3}{|c|}{ experiment } \\
\hline $\begin{array}{c}\tilde{v} \\
\left(\mathrm{~cm}^{-1}\right)\end{array}$ & $\begin{array}{c}A \\
\mathrm{~km} / \mathrm{mol}\end{array}$ & $I_{\text {rel }}$ & $\Gamma$ & $\begin{array}{c}\tilde{v} \\
\left(\mathrm{~cm}^{-1}\right)\end{array}$ & $\begin{array}{c}A \\
\mathrm{~km} / \mathrm{mol}\end{array}$ & $I_{\text {rel }}$ & $\begin{array}{c}\tilde{v} \\
\left(\mathrm{~cm}^{-1}\right)\end{array}$ & $\begin{array}{c}A \\
\mathrm{~km} / \mathrm{mol}\end{array}$ & $I_{\text {rel }}$ & $\Gamma$ & $\begin{array}{c}\tilde{v} \\
\left(\mathrm{~cm}^{-1}\right)\end{array}$ & $\begin{array}{c}A \\
\mathrm{~km} / \mathrm{mol}\end{array}$ & $I_{\text {rel }}$ \\
\hline 626.1 & 6.2 & 0.121 & $A^{\prime}$ & $618.6,619.9$ & 5.0 & 0.11 & 716.7 & 36.4 & 0.712 & $\mathrm{~B}_{1}$ & $717.6^{*}$ & 44.2 & 1.00 \\
\hline 731.1 & 8.5 & 0.166 & $\mathrm{~A}^{\prime \prime}$ & 722.3 & 14.0 & 0.30 & 797.8 & 7.8 & 0.153 & $A_{1}$ & 804.7 & 6.3 & 0.14 \\
\hline 749.4 & 51.2 & 1.000 & $A^{\prime \prime}$ & $745.9 *$ & 46.5 & 1.00 & 807.0 & 11.5 & 0.224 & $\mathrm{~B}_{1}$ & 816.5 & 21.0 & 0.48 \\
\hline \multirow[t]{2}{*}{821.1} & 41.8 & 0.817 & $\mathrm{~A}^{\prime \prime}$ & 807.6 & 16.6 & 0.36 & 819.8 & 4.9 & 0.096 & $\mathrm{~A}_{1}$ & $822.4^{*}$ & 9.2 & 0.21 \\
\hline & & & & 826.6 & 9.1 & 0.20 & 839.6 & 51.1 & 1.000 & $\mathrm{~B}_{1}$ & $846.8^{*}$ & 21.7 & 0.49 \\
\hline 852.6 & 26.5 & 0.517 & $A^{\prime \prime}$ & $834.0^{*}$ & 35.3 & 0.76 & 904.9 & 41.4 & 0.810 & $\mathrm{~B}_{1}$ & $893.7 *$ & 25.2 & 0.57 \\
\hline 942.7 & 0.9 & 0.018 & $\mathrm{~A}^{\prime \prime}$ & $953.9 *$ & 7.0 & 0.15 & & & & & 1024.9 & 5.7 & 0.13 \\
\hline 964.1 & 2.2 & 0.043 & $A^{\prime \prime}$ & & & & 1077.8 & 3.5 & 0.068 & $\mathrm{~A}_{1}$ & 1077.1 & 5.2 & 0.12 \\
\hline 1013.9 & 4.5 & 0.088 & $\mathrm{~A}^{\prime}$ & 1018.2 & 4.6 & 0.10 & 1123.8 & 7.7 & 0.151 & $A_{1}$ & $1142.1,1143.3$ & 13.9 & 0.31 \\
\hline 1084.3 & 4.2 & 0.081 & $\mathrm{~A}^{\prime}$ & 1095.2 & 4.9 & 0.10 & 1187.8 & 6.2 & 0.122 & $\mathrm{~B}_{2}$ & $1180.2,1183.0$ & 8.2 & 0.19 \\
\hline 1141.2 & 0.6 & 0.013 & $\mathrm{~A}^{\prime}$ & 1133.4 & 5.1 & 0.11 & 1210.7 & 4.6 & 0.090 & $\mathrm{~B}_{2}$ & 1208.0 & 6.6 & 0.15 \\
\hline 1388.9 & 35.0 & 0.683 & $\mathrm{~A}^{\prime}$ & $1405.7 *$ & 23.9 & 0.52 & 1245.8 & 0.9 & 0.018 & $\mathrm{~A}_{1}$ & 1239.4 & 10.4 & 0.24 \\
\hline 1439.1 & 13.4 & 0.262 & $\mathrm{~A}^{\prime}$ & $1447.7 *$ & 19.3 & 0.42 & 1259.2 & 4.2 & 0.083 & $\mathrm{~A}_{1}$ & $1254.4 *$ & 8.9 & 0.20 \\
\hline 1445.8 & 9.1 & 0.178 & $\mathrm{~A}^{\prime}$ & & & & 1382.1 & 6.8 & 0.132 & $\mathrm{~B}_{2}$ & 1385.0 & 4.2 & 0.09 \\
\hline 1489.8 & 6.1 & 0.120 & $\mathrm{~A}^{\prime}$ & 1500.4 & 8.6 & 0.18 & 1425.2 & 3.8 & 0.075 & $\mathrm{~B}_{2}$ & 1422.7 & 1.3 & 0.17 \\
\hline 1499.4 & 15.4 & 0.300 & $\mathrm{~A}^{\prime}$ & $1515.5^{*}$ & 7.6 & 0.16 & 1429.8 & 14.8 & 0.289 & $\mathrm{~A}_{1}$ & 1427.5 & 0.03 & 0.004 \\
\hline 1575.4 & 12.3 & 0.239 & $\mathrm{~A}^{\prime}$ & $1574.1,1576.3$ & 4.7 & 0.10 & 1439.1 & 6.1 & 0.120 & $\mathrm{~A}_{1}$ & $1433.3^{*}$ & 3.7 & 0.08 \\
\hline \multirow[t]{3}{*}{1597.2} & 4.2 & 0.083 & $\mathrm{~A}^{\prime}$ & 1596.2 & 15.2 & 0.33 & & & & & $1460.5^{*}$ & 9.2 & 0.21 \\
\hline & & & & & & & 1561.2 & 5.2 & 0.101 & $\mathrm{~B}_{2}$ & $1542.9^{*}$ & 8.0 & 0.18 \\
\hline & & & & & & & 1588.7 & 11.3 & 0.222 & $\mathrm{~B}_{2}$ & 1572.9 & 3.7 & 0.08 \\
\hline \multicolumn{4}{|c|}{$\begin{array}{c}3049.8,3055.3,3059.4,3065.2 \\
3076.1,3086.7,3102.6\end{array}$} & \multicolumn{3}{|c|}{$\begin{array}{l}2932,2965,3034 \\
3060^{*}, 3099\end{array}$} & \multicolumn{4}{|c|}{$\begin{array}{c}\text { 3045.2, 3052.0, } 3058.4 \\
3068.1,3077.4\end{array}$} & \multicolumn{3}{|c|}{$\begin{array}{l}3012,3018,3029 \\
3042 *, 3051,3057\end{array}$} \\
\hline IM & 1733 & 338 & $A^{\prime}$ & UIM & 882 & 190 & UIM & 1733 & 339 & & SuM & 67.5 & 15. \\
\hline
\end{tabular}

${ }^{a}$ Data truncated at the $10 \%$ relative intensity level. The complete, untruncated tables are available electronically at www.astrochemistry.org/ pahdata/index.html. The * indicates strongest member of a multiplet.

sene cation observed at 777.3 and $754.4 \mathrm{~cm}^{-1}$ (theory: 781.5 and $758.9 \mathrm{~cm}^{-1}$ ). These positions are nearly identical to the corresponding features of the neutral molecule visible at 778.1 and $753.2 \mathrm{~cm}^{-1}$ (theory: 781.5 and $755.5 \mathrm{~cm}^{-1}$ ). Indeed, these cation features are completely subsumed by their stronger, neutral counterparts in the post-photolysis spectrum and are 
TABLE 4: Comparison of the Total Absolute Absorption Intensities of PANHs to Their Parent PAHs in the 1100-500, $1600-1100$, and $3150-2950 \mathrm{~cm}^{-1}$ Regions of the Spectrum

\begin{tabular}{|c|c|c|c|c|c|c|}
\hline & \multicolumn{3}{|c|}{ experiment } & \multicolumn{3}{|c|}{ theory } \\
\hline & $\sum_{1100>\tilde{v}>500} A$ & $\sum_{1600>\tilde{v}>1100} A$ & $\sum_{3150>\tilde{v}>2950} A$ & $\sum_{1100>\tilde{v}>500} A$ & $\sum_{1600>\tilde{v}>1100} A$ & $\sum_{3150>\tilde{v}>2950} A^{a}$ \\
\hline \multicolumn{7}{|l|}{ PAHs (values in $\mathrm{km} / \mathrm{mol}$ ) } \\
\hline phenanthrene & 176 & 48 & 126 & 167 & 52 & 199 \\
\hline pyrene & 186 & 54 & 102 & 176 & 58 & 217 \\
\hline benz $[a]$ anthracene & 203 & 65 & 120 & 204 & 69 & 242 \\
\hline chrysene & 217 & 63 & 126 & 210 & 70 & 236 \\
\hline \multicolumn{7}{|l|}{ PANHs (values in $\mathrm{km} / \mathrm{mol}$ ) } \\
\hline 7,8-benzoquinoline & 164 & 113 & 88 & 166 & 126 & 177 \\
\hline 2-azapyrene & 157 & 100 & 76 & 171 & 102 & 181 \\
\hline 1-azabenz $[a]$ anthracene & 197 & 165 & 132 & 193 & 176 & 221 \\
\hline 2-azabenz $[a]$ anthracene & 209 & 123 & 86 & 194 & 142 & 218 \\
\hline 1-azachrysene & 181 & 136 & 57 & 198 & 130 & 202 \\
\hline 2-azachrysene & 218 & 128 & 92 & 210 & 152 & 207 \\
\hline 4-azachrysene & 150 & 135 & 84 & 206 & 160 & 216 \\
\hline \multicolumn{7}{|l|}{ ratios } \\
\hline 7,8-benzoquinoline/phenanthrene & 0.93 & 2.37 & 0.70 & 0.99 & 2.39 & 0.89 \\
\hline 2-azapyrene/pyrene & 0.84 & 1.86 & 0.74 & 0.97 & 1.76 & 0.83 \\
\hline 1 -azabenz $[a]$ anth./benz $[a]$ anth. & 0.97 & 2.53 & 1.10 & 0.95 & 2.55 & 0.91 \\
\hline 2-azabenz $[a]$ anth./benz $[a]$ anth. & 1.03 & 1.88 & 0.71 & 0.95 & 2.05 & 0.90 \\
\hline 1-azachrysene/chrysene & 0.83 & 2.17 & 0.45 & 0.94 & 1.85 & 0.86 \\
\hline 2-azachrysene/chrysene & 1.01 & 2.03 & 0.73 & 1.00 & 2.16 & 0.88 \\
\hline 4-azachrysene/chrysene & 0.69 & 2.14 & 0.66 & 0.98 & 2.28 & 0.92 \\
\hline average & 0.90 & 2.14 & 0.73 & 0.97 & 2.15 & 0.88 \\
\hline
\end{tabular}

${ }^{a}$ The theoretical $\mathrm{CH}$ stretching intensities are not corrected for the expected factor of $\approx 2$ overestimate associated with calculations at the B3LYP/ 4-31G level (see section II.B). ${ }^{3 a}$

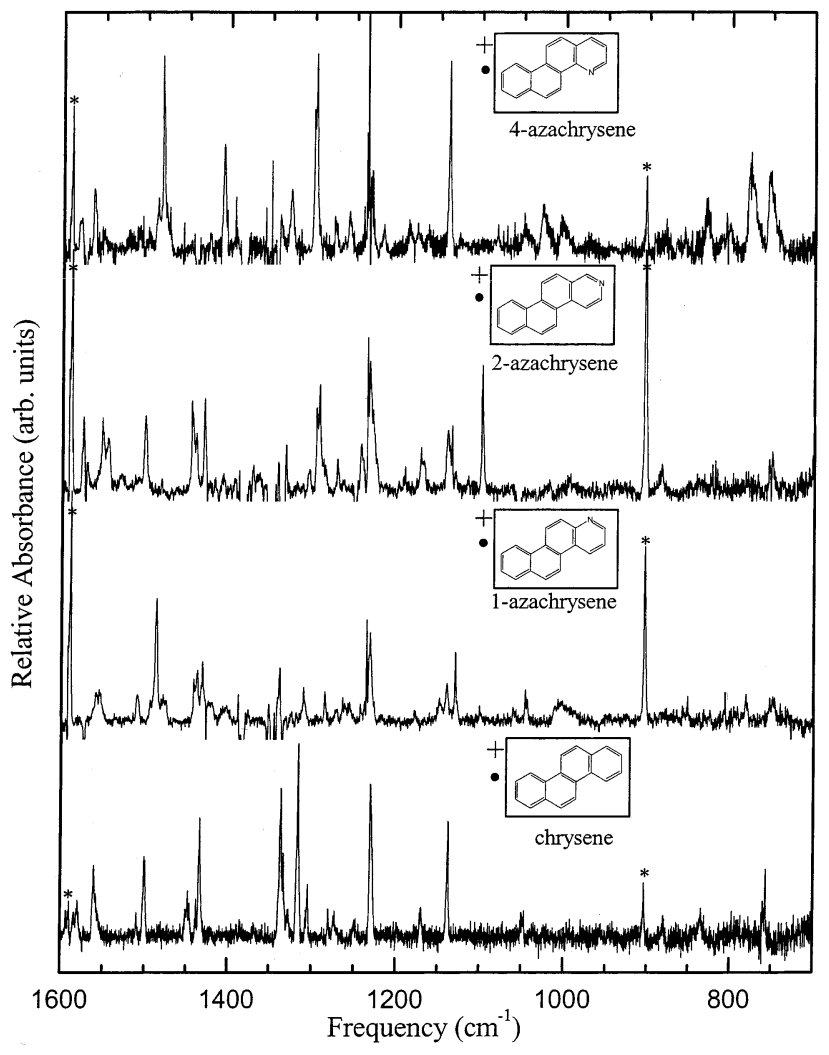

Figure 7. Mid-infrared spectra of the 1-, 2-, and 4-azachrysene cations isolated in argon matrixes at $14 \mathrm{~K}$. The spectrum of the chrysene cation is shown for reference. The spectra are the difference between the spectra of the argon matrix-isolated samples measured before and after photolysis. The bands marked by an asterisk (*) are contaminant photoproducts.

observable in the difference spectrum (Figure 7) only by virtue of their intrinsic strength. For weaker bands, this will not be the case, and it is likely that a high proportion of these bands are not observable in the experimental data. This is particularly true for the $\mathrm{CH}$ stretching region between 3100 and $3000 \mathrm{~cm}^{-1}$
TABLE 5: Comparison of the Average Mulliken Populations on the Carbon Atoms of Several PANHs and Their Corresponding Parent Aromatic Hydrocarbons

\begin{tabular}{lcc}
\hline \multirow{2}{*}{ molecule } & \multicolumn{2}{c}{$\begin{array}{c}\text { average Mulliken population } \\
\text { on skeletal carbon atoms }\end{array}$} \\
\cline { 2 - 3 } & neutral & cation \\
\hline phenanthrene & -0.091 & -0.066 \\
7,8-benzoquinoline & -0.058 & -0.029 \\
pyrene & -0.080 & -0.057 \\
2-azapyrene & -0.054 & -0.028 \\
benz[a]anthracene & -0.086 & -0.065 \\
1-azabenz[a]anthracene & -0.060 & -0.037 \\
2-azabenz[a]anthracene & -0.063 & -0.042 \\
chrysene & -0.086 & -0.066 \\
1-azachrysene & -0.060 & -0.039 \\
2-azachrysene & -0.064 & -0.042 \\
4-azachrysene & -0.060 & -0.037
\end{tabular}

where, as has been the case with previous IR studies of positively charged aromatic molecules, the strongly suppressed cation bands cannot be differentiated from the strong bands of the parent neutral. Again, relative intensity differences are greater than those associated with the band positions, with differences of a factor of 2 being common and some considerably higher.

Overall, the effects of ionization on the infrared spectra of PANHs are similar to those observed previously for PAHs. These effects are quantified in Table 9 which compares the total theoretically calculated absorption intensities in the 1100-500, $1600-1100$, and $3150-2950 \mathrm{~cm}^{-1}$ regions for PANHs in their neutral and cationic forms. The analogous experimental data is not shown because of the incomplete coverage of these features in that data as discussed above. For the bands in the 3150$2950 \mathrm{~cm}^{-1}$ region, the effect of ionization on the PANH spectra is identical to that observed for the analogous PAHs and involves a suppression by nearly an order of magnitude. Summing the intensities of the bands in the $1100-500 \mathrm{~cm}^{-1}$ region, we find a modest but significant $40 \%$ enhancement of the total absorption intensity in this region. This result would seem to be at odds with our previous reports that the strongest $\mathrm{CH}$ out-of- 


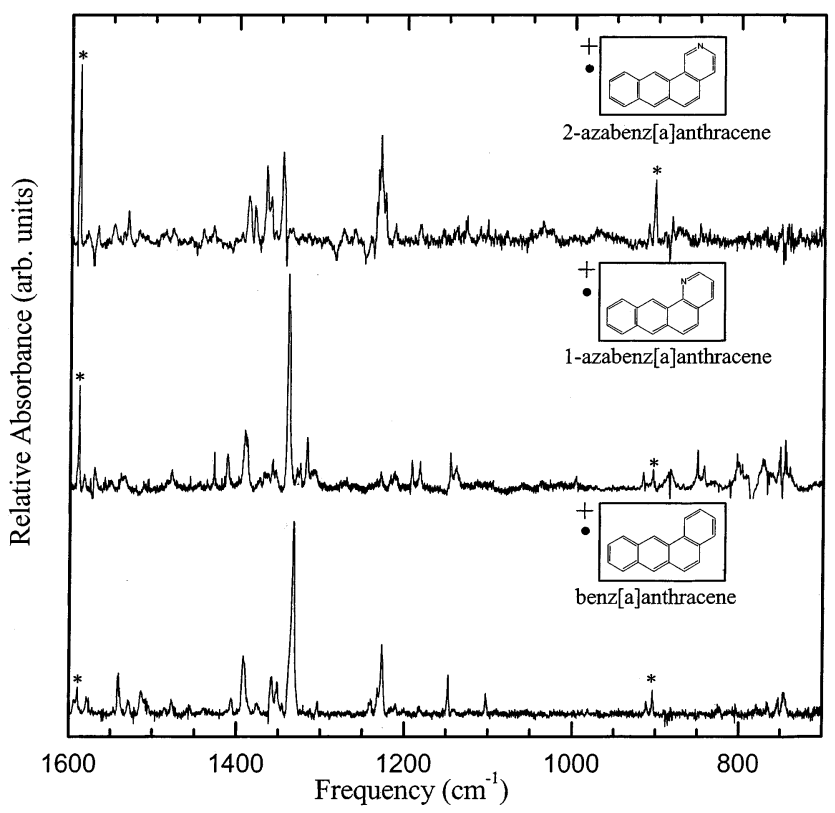

Figure 8. Mid-infrared spectra of the 1- and 2-azabenz $[a]$ anthracene cations isolated in argon matrixes at $14 \mathrm{~K}$. The spectrum of the benz$[a]$ anthracene cation is shown for reference. The spectra are the difference between the spectra of samples measured before and after in-situ photolysis. Because of experimental difficulties, the 2-azabenz$[a]$ anthracene spectrum is a combination of data from two experiments. The $1600-1000 \mathrm{~cm}^{-1}$ portion of the spectrum is taken from a neat argon matrix-isolated sample, whereas the $1000-700 \mathrm{~cm}^{-1}$ portion is taken from a sample in which the argon matrix was doped with the electron acceptor $\mathrm{NO}_{2}\left(\mathrm{Ar} / \mathrm{NO}_{2} \sim 1000 / 1\right)$. The two spectra were scaled to compensate for differences in the ion yields of the two experiments. The bands marked by an asterisk (*) are contaminant photoproducts.

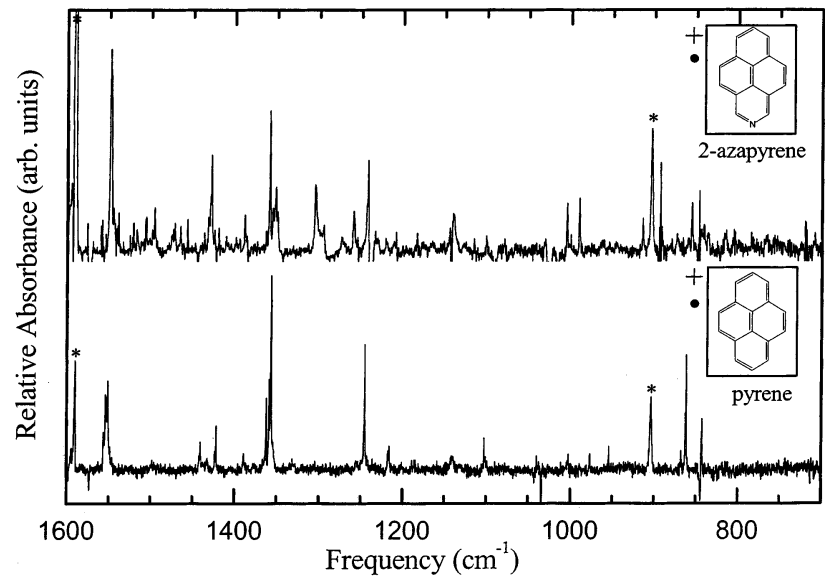

Figure 9. Mid-infrared spectra of the 2-azapyrene cation isolated in an argon matrix at $14 \mathrm{~K}$. The spectrum of the pyrene cation is shown for reference. The spectra are the difference between the spectra of the argon matrix-isolated samples measured before and after photolysis. The bands marked by an asterisk (*) are contaminant photoproducts.

plane bending modes of PAHs are modestly suppressed by ionization. ${ }^{8 \mathrm{~b}, \mathrm{c}, \mathrm{d}, \mathrm{h}}$ However, those earlier reports focused individually on only the strongest bands in this region, not the composite behavior of all of the bands in the region. Indeed, employing the analogous analysis, ${ }^{8 b}$ the experimental PANH data do indicate that, ionization produces a suppression of the individual PANH CH out-of-plane bands entirely consistent with that noted previously for the parent aromatic hydrocarbons. Clearly, there is sufficient enhancement in the other modes that fall in this region of the mid-infrared (e.g., skeletal distortion modes) that, taken as a group, the total integrated intensity increases. For comparison, the DFT calculations indicate that the individual
$\mathrm{CH}$ out-of-plane modes in PANHs are, on average, virtually unchanged by ionization. Thus, these data are also in agreement that the observed global enhancement of the intensity in the 1100-500 $\mathrm{cm}^{-1}$ region arises from modes other than the dominant $\mathrm{CH}$ out-of-plane bends.

Although the $1600-1100 \mathrm{~cm}^{-1}$ modes in PANHs are strongly enhanced by ionization, that enhancement is roughly half that observed for the analogous PAHs. This is understandable in terms of the pseudoionization effect that substitution of the electronegative nitrogen atom into the carbon skeleton has on these modes (see section III.A) - the charge distribution on the carbon skeleton of a neutral PANH is already intermediate between that of a neutral PAH and that of its (the PANHs) cation; consequently, the magnitude of the ionization effect is somewhat attenuated. Taking all of the above into account, the total absorption intensities of the PANH cations do not differ significantly from that of the analogous PAH cations.

In the previous section, it was noted that the higher electronegativity of the nitrogen atom decreases the electron density surrounding the carbon atoms in the neutral PANH, creating the pseudoionization effect and enhancing $\mathrm{CC}$ and $\mathrm{CH}$ modes. It is natural to expect that the formation of a PANH cation, which would lower the electron density surrounding the nitrogen atom, would significantly enhance the nitrogen-dominated modes. Indeed, according to the Gaussian results, modes exhibiting appreciable amounts of nitrogen motion exhibit enhancements analogous to those observed in the CC stretching and $\mathrm{CH}$ in-plane bending modes. The characteristic regions for the nitrogen dominated modes are similar to those observed for the neutral species: $1100-1000 \mathrm{~cm}^{-1}$ for modes involving significant $\mathrm{CN}$ stretching or CNC in-plane bending; 600-500 $\mathrm{cm}^{-1}$ and below for modes involving significant $\mathrm{CNC}$ out-ofplane warping.

C. PANH Dipole Moments. By virtue of their permanent dipole moments, PANHs will exhibit pure rotational spectra, making them potentially attractive candidates for an astronomical search. In view of this potential, the rotational constants and dipole moments for the species studied here have also been calculated using the Gaussian output. The components of the dipole moment along each of the molecules' principal axes of inertia and the rotational constants about each of these axes are summarized in Table 10. Calibration calculations, at the same level of theory, for the benzene molecule yield rotational constants that are accurate to within $1 \%$.

All of the PANH species considered in this study are asymmetric top molecules (i.e., the moments of inertia about each of the molecule's three internal coordinate axes is different). The rotational axes of each molecule are identified as $a, b$, and $c$ on the basis of the moment of inertia, $I$, about each axis and according to the convention $I_{a}<I_{b}<I_{c}$. The rotational constants about the $a, b$, and $c$ axes are denoted $A$, $B$, and $C$, respectively and are determined by the standard expression

$$
Q=\frac{\hbar}{4 \pi c I_{q}}
$$

where $Q$ ( $=A, B$, or $C$ ) is the rotational constant and $I_{q}$ is the moment of inertia about the $q$ axis. These rotational constants correspond to rotational transitions that fall in the centimeterwavelength range of the electromagnetic spectrum.

The B3LYP dipole moments are computed at the center of mass of each molecule, with the $x$ (horizontal), $y$ (vertical), and $z$ (normal to the plane of the figure) axes aligned along the principal axes of inertia. The magnitude and direction of these 
TABLE 6: Theoretical and Experimental Band Positions and Intensities for the Azachrysene Cations ${ }^{a}$

\begin{tabular}{|c|c|c|c|c|c|c|c|c|c|c|c|c|c|c|c|c|c|}
\hline \multicolumn{6}{|c|}{ 1-azachrysene } & \multicolumn{6}{|c|}{ 2-azachrysene } & \multicolumn{6}{|c|}{ 4-azachrysene } \\
\hline \multicolumn{4}{|c|}{ theory } & \multicolumn{2}{|c|}{ experiment } & \multicolumn{4}{|c|}{ theory } & \multicolumn{2}{|c|}{ experiment } & \multicolumn{4}{|c|}{ theory } & \multicolumn{2}{|c|}{ experiment } \\
\hline $\begin{array}{c}\tilde{v} \\
\left(\mathrm{~cm}^{-1}\right)\end{array}$ & $\begin{array}{c}A \\
\mathrm{~km} / \mathrm{mol}\end{array}$ & $I_{\text {rel }}$ & $\Gamma$ & $\begin{array}{c}\tilde{v} \\
\left(\mathrm{~cm}^{-1}\right)\end{array}$ & $I_{\text {rel }}$ & $\begin{array}{c}\tilde{v} \\
\left(\mathrm{~cm}^{-1}\right)\end{array}$ & $\begin{array}{c}A \\
\mathrm{~km} / \mathrm{mol}\end{array}$ & $I_{\text {rel }}$ & $\Gamma$ & $\begin{array}{c}\tilde{v} \\
\left(\mathrm{~cm}^{-1}\right)\end{array}$ & $I_{\mathrm{rel}}$ & $\begin{array}{c}\tilde{v} \\
\left(\mathrm{~cm}^{-1}\right)\end{array}$ & $\begin{array}{c}A \\
\mathrm{~km} / \mathrm{mol}\end{array}$ & $I_{\text {rel }}$ & $\Gamma$ & $\begin{array}{c}\tilde{v} \\
\left(\mathrm{~cm}^{-1}\right)\end{array}$ & $I_{\text {rel }}$ \\
\hline 543.6 & 3.5 & 0.012 & $\mathrm{~A}^{\prime}$ & 547.1 & 0.44 & 757.3 & 39.7 & 0.106 & $\mathrm{~A}^{\prime \prime}$ & 750.6 & 0.06 & 561.1 & 20.9 & 0.064 & $\mathrm{~A}^{\prime}$ & 552.6 & 0.20 \\
\hline 757.0 & 34.9 & 117 & $A^{\prime \prime}$ & 752.6 & 0.07 & 820.7 & 40.2 & 0.107 & $A^{\prime \prime}$ & 822.7 & 0.06 & 758.9 & 53.3 & 0.162 & $A^{\prime \prime}$ & 754.4 & 0.66 \\
\hline 778.0 & 16.7 & 0.056 & $A^{\prime \prime}$ & 781.4 & 0.10 & 1093.3 & 61.7 & 0.165 & $\mathrm{~A}^{\prime}$ & 1098.7 & 0.31 & & & & & 777.3 & 0.86 \\
\hline 811.3 & 52.0 & 0.174 & $A^{\prime \prime}$ & 806.5 & 0.08 & 1139.0 & 64.2 & 0.172 & $\mathrm{~A}^{\prime}$ & & & 1151.9 & 83.2 & 0.253 & $\mathrm{~A}^{\prime}$ & 1139.0 & 0.68 \\
\hline 858.3 & 42.8 & 0.143 & $\mathrm{~A}^{\prime \prime}$ & 851.4 & 0.04 & 1178.3 & 40.9 & 0.109 & $\mathrm{~A}^{\prime}$ & & & 1218.5 & 57.6 & 0.175 & $\mathrm{~A}^{\prime}$ & & \\
\hline & & & & 864.7 & 0.02 & 1229.7 & 296.8 & 0.794 & $\mathrm{~A}^{\prime}$ & 1233.6 & 0.57 & 1232.7 & 101.4 & 0.309 & $\mathrm{~A}^{\prime}$ & & \\
\hline 1037.4 & 42.7 & 0.143 & $\mathrm{~A}^{\prime}$ & $1046.1 *$ & 0.14 & 1249.1 & 42.2 & 0.113 & $\mathrm{~A}^{\prime}$ & & & 1248.3 & 9.6 & 0.029 & $\mathrm{~A}^{\prime}$ & 1258.9 & 0.17 \\
\hline & 28.6 & 0.096 & $\mathrm{~A}^{\prime}$ & 1060.9 & 0.12 & 90.2 & 159.4 & 0.427 & $\mathrm{~A}^{\prime}$ & $1293.3^{*}$ & 1.00 & 1273.7 & 3.1 & 0.009 & $\mathrm{~A}^{\prime}$ & 127 & 0.14 \\
\hline 1130.9 & 43.5 & 0.146 & $\mathrm{~A}^{\prime}$ & 1130.0 & 0.32 & 1305.2 & 15.8 & 0.042 & $\mathrm{~A}^{\prime}$ & & & 1287.4 & 328.4 & 1.000 & $\mathrm{~A}^{\prime}$ & $1297.9 *$ & 1.00 \\
\hline 1150.6 & 24.6 & 0.082 & $\mathrm{~A}^{\prime}$ & 1148.7 & 0.11 & 1315.7 & 20.8 & 0.056 & $\mathrm{~A}^{\prime}$ & & & 1326.6 & 92.9 & 0.283 & $\mathrm{~A}^{\prime}$ & 1327.6 & 0.26 \\
\hline 1188.3 & 18.2 & 0.061 & $\mathrm{~A}^{\prime}$ & $1178.9 *$ & 0.10 & 1339.9 & 219.7 & 0.588 & $\mathrm{~A}^{\prime}$ & & & 1341.1 & 39.9 & 0.122 & $\mathrm{~A}^{\prime}$ & & \\
\hline 1230.8 & 107.8 & 0.361 & $\mathrm{~A}^{\prime}$ & 1231.9 & 0.62 & 1425.5 & 61.8 & 0.165 & $\mathrm{~A}^{\prime}$ & 1430.4 & 0.23 & 1367.1 & 53.5 & 0.163 & $\mathrm{~A}^{\prime}$ & & \\
\hline 1237.7 & 58.5 & 0.196 & $\mathrm{~A}^{\prime}$ & & & 1440.2 & 47.1 & 0.126 & $A^{\prime}$ & $1446.2 *$ & 0.47 & 1420.7 & 40.8 & 0.124 & $\mathrm{~A}^{\prime}$ & & \\
\hline 1286.0 & 23.8 & 0.080 & $\mathrm{~A}^{\prime}$ & 1285.0 & 0.11 & 1492.6 & 110.3 & 0.295 & $\mathrm{~A}^{\prime}$ & 1481.9 & 0.04 & 1467.8 & 232.1 & 0.707 & $\mathrm{~A}^{\prime}$ & $1482.0 *$ & 0.78 \\
\hline 1301.2 & 73.5 & 0.246 & $\mathrm{~A}^{\prime}$ & 1310.5 & 0.19 & 1512.3 & 256.2 & 0.686 & $\mathrm{~A}^{\prime}$ & & & 1487.3 & 114.5 & 0.349 & $\mathrm{~A}^{\prime}$ & & \\
\hline 1339.5 & 211.3 & 0.707 & $\mathrm{~A}^{\prime}$ & 1338.7 & 0.45 & 1528.7 & 373.7 & 1.000 & $\mathrm{~A}^{\prime}$ & $1553.0^{*}$ & 0.65 & 1530.4 & 234.1 & 0.713 & $\mathrm{~A}^{\prime}$ & & \\
\hline 1353.4 & 42.4 & 0.142 & $\mathrm{~A}^{\prime}$ & 1351.0 & 0.09 & 1539.8 & 54.0 & 0.144 & $\mathrm{~A}^{\prime}$ & & & 1542.3 & 139.5 & 0.425 & $\mathrm{~A}^{\prime}$ & 1564.4 & 0.43 \\
\hline 1419.4 & 78.4 & 0.262 & $\mathrm{~A}^{\prime}$ & 1431.7 & 0.17 & 1551.1 & 222.9 & 0.596 & $\mathrm{~A}^{\prime}$ & 1575.5 & 0.20 & 1552.6 & 109.1 & 0.332 & $\mathrm{~A}^{\prime}$ & 1579.3 & 0.23 \\
\hline 1438.2 & 15.5 & 0.052 & $\mathrm{~A}^{\prime}$ & $1437.5 *$ & 0.36 & & & & & & & 1576.7 & 12.6 & 0.039 & $\mathrm{~A}^{\prime}$ & & \\
\hline 1479.7 & 298.9 & 1.000 & $\mathrm{~A}^{\prime}$ & 1478.7 & 0.19 & & & & & & & & & & & & \\
\hline
\end{tabular}

$\begin{array}{llllll}1485.2 & 10.3 & 0.035 & \mathrm{~A}^{\prime} & 1487.1 & 1.00\end{array}$

$\begin{array}{llllll}1501.9 & 125.5 & 0.420 & \mathrm{~A}^{\prime} & 1494.1 & 0.03\end{array}$

$\begin{array}{rrrrrr}1515.6 & 81.6 & 0.273 & \mathrm{~A}^{\prime} & 1509.3 & 0.17\end{array}$

$\begin{array}{llll}1529.6 & 101.2 & 0.339 & \mathrm{~A}^{\prime}\end{array}$

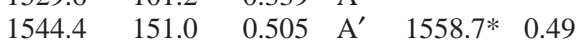

3086.5, 3093.3, 3102.3, 3106.6, $3107.9,3115.0,3120.6$

3066.5, 3104.4, 3106.5, 3116.9

$\begin{array}{llll}\text { SUM } & 25.5 & 0.068 & \mathrm{~A}^{\prime}\end{array}$
3087.1, 3105.9, 3108.8, $3109.7,3114.2$

$\begin{array}{llll}\text { SUM } & 28.6 & 0.087 & \mathrm{~A}^{\prime}\end{array}$

SUM $\quad 34.0 \quad 0.114 \quad \mathrm{~A}^{\prime}$

${ }^{a}$ Data for $\tilde{v}<1600 \mathrm{~cm}^{-1}$ truncated at the $10 \%$ relative intensity level; data for $3120<\tilde{v}<3000 \mathrm{~cm}^{-1}$ truncated at the $1 \%$ relative intensity level. The complete, untruncated tables are available electronically at www.astrochemistry.org/pahdata/index.html. The * indicates the strongest member of a multiplet.

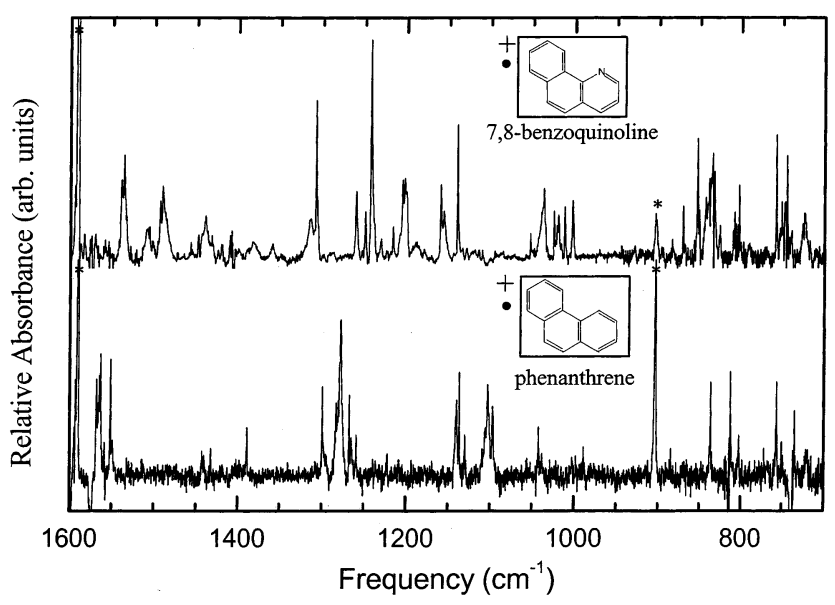

Figure 10. Mid-infrared spectra of the 7,8-benzoquinoline cation isolated in an argon matrix at $14 \mathrm{~K}$. The spectrum of the phenanthrene cation is shown for reference. These spectra are the difference between the spectra of samples measured before and after in-situ photolysis. Because of experimental difficulties, the 7,8-benzoquinoline cation spectrum is a combination of data from two experiments. The 1600$1000 \mathrm{~cm}^{-1}$ portion of the spectrum is taken from a sample in which the argon matrix was doped with 1 part in 1000 of $\mathrm{CCl}_{4}$, whereas the $1000-700 \mathrm{~cm}^{-1}$ portion is taken from a sample in which the argon matrix was doped with 1 part in 1000 of $\mathrm{NO}_{2}$. The two spectra were scaled to compensate for differences in the ion yields of the two experiments. The bands marked by an asterisk (*) are argon photolysis products.

dipole moments are indicated by the arrows next to each structure in Figure 1. Arrows for both the neutral (black) and cationic (gray) forms of each species are included in the diagram and the arrows point from the negative to the positive end of the associated dipole. Perusal of Figure 1 and Table 10 shows that, on average, PANHs all possess substantial dipole moments with those of ionized PANHs being somewhat larger than neutral PANHs. Neutral PANHs have dipole moments which range from 1.67 to $3.37 \mathrm{D}$, whereas the values for positively charged PANHs lie between 2.24 and 5.44 D. For these planar species, the components of these dipole moments are necessarily confined to the plane of the molecule, as observed in Table 10 $\left(\mu_{c} \equiv 0\right.$ in all cases). For reference, the experimental ${ }^{17}$ (theoretical) dipole moments for $\mathrm{CO}, \mathrm{H}_{2} \mathrm{CO}$, and $\mathrm{HC}_{3} \mathrm{~N}$ are 0.117 (0.158), 2.34 (2.45), and 3.6 (3.86) Debye, respectively.

\section{Conclusions}

The mid-infrared spectra of the argon matrix isolated, $\mathrm{N}$-containing aromatic compounds 7,8-benzoquinoline $\left(\mathrm{C}_{13} \mathrm{H}_{9} \mathrm{~N}\right)$, 2-azapyrene $\left(\mathrm{C}_{15} \mathrm{H}_{9} \mathrm{~N}\right)$, 1- and 2- azabenz $[a]$ anthracene $\left(\mathrm{C}_{17} \mathrm{H}_{11} \mathrm{~N}\right)$, and 1-, 2-, and 4-azachrysene (also $\mathrm{C}_{17} \mathrm{H}_{11} \mathrm{~N}$ ) in their neutral and cation forms are reported. Comparisons between these spectra and spectra computed using density functional theory at the B3LYP/4-31G level is good, consistent with earlier comparisons on homonuclear polycyclic aromatic hydrocarbons.

Nitrogen insertion induces several new spectroscopic trends for the aromatic family of molecules. For the neutral species, nitrogen inclusion causes characteristic intensity enhancements for bands between 1600 and $1100 \mathrm{~cm}^{-1}$, the CC stretching and $\mathrm{CH}$ in-plane bending vibrations, and increases the IR activity near $1400 \mathrm{~cm}^{-1}$, corresponding to a mode which is characteristic of a particular $\mathrm{N}$ substitution site. Upon ionization, the spectral effects are similar to those reported previously for the corre- 
TABLE 7: Theoretical and Experimental Band Positions and Intensities for the Azabenz $[a]$ anthracene Cations ${ }^{a}$

\begin{tabular}{|c|c|c|c|c|c|c|c|c|c|c|c|}
\hline \multicolumn{6}{|c|}{ 1-azabenz $[a]$ nthracene } & \multicolumn{6}{|c|}{ 2-azabenz $[a]$ anthracene } \\
\hline \multicolumn{4}{|c|}{ theory } & \multicolumn{2}{|c|}{ experiment } & \multicolumn{4}{|c|}{ theory } & \multicolumn{2}{|c|}{ experiment } \\
\hline $\begin{array}{c}\tilde{v} \\
\left(\mathrm{~cm}^{-1}\right)\end{array}$ & $\begin{array}{c}A \\
\mathrm{~km} / \mathrm{mol}\end{array}$ & $I_{\text {rel }}$ & $\Gamma$ & $\begin{array}{c}\tilde{v} \\
\left(\mathrm{~cm}^{-1}\right)\end{array}$ & $I_{\text {rel }}$ & $\begin{array}{c}\tilde{v} \\
\left(\mathrm{~cm}^{-1}\right)\end{array}$ & $\begin{array}{c}A \\
\mathrm{~km} / \mathrm{mol}\end{array}$ & $I_{\text {rel }}$ & $\Gamma$ & $\begin{array}{c}\tilde{v} \\
\left(\mathrm{~cm}^{-1}\right)\end{array}$ & $I_{\text {rel }}$ \\
\hline 756.9 & 45.1 & 0.114 & $\mathrm{~A}^{\prime \prime}$ & 752.1 & 0.03 & 668.6 & 6.9 & 0.029 & $\mathrm{~A}^{\prime}$ & 664.0 & 0.12 \\
\hline 774.9 & 21.0 & 0.053 & $\mathrm{~A}^{\prime \prime}$ & & & 755.7 & 48.5 & 0.206 & $\mathrm{~A}^{\prime \prime}$ & & \\
\hline 820.0 & 26.1 & 0.066 & $A^{\prime \prime}$ & 803.4 & 0.06 & 854.2 & 28.2 & 0.120 & $A^{\prime \prime}$ & 848.9 & 0.07 \\
\hline 918.6 & 29.6 & 0.075 & $A^{\prime \prime}$ & 915.6 & 0.03 & 912.2 & 40.1 & 0.170 & $A^{\prime \prime}$ & 910.7 & 0.06 \\
\hline 1156.0 & 28.5 & 0.072 & $\mathrm{~A}^{\prime}$ & 1146.4 & 0.07 & 1192.3 & 33.1 & 0.140 & $A^{\prime}$ & 1184.1 & 0.11 \\
\hline 1186.8 & 0.6 & 0.002 & $\mathrm{~A}^{\prime}$ & 1182.9 & 0.08 & 1222.6 & 42.6 & 0.181 & $\mathrm{~A}^{\prime}$ & 1213.6 & 0.16 \\
\hline 1190.3 & 27.4 & 0.069 & $A^{\prime}$ & 1192.7 & 0.05 & 1236.7 & 187.1 & 0.793 & $\mathrm{~A}^{\prime}$ & 1230.8 & 1.00 \\
\hline 1208.9 & 89.0 & 0.225 & $\mathrm{~A}^{\prime}$ & $1212.8^{*}$ & 0.14 & 1332.8 & 219.7 & 0.931 & $\mathrm{~A}^{\prime}$ & 1347.6 & 0.44 \\
\hline 1233.1 & 37.9 & 0.096 & $\mathrm{~A}^{\prime}$ & 1229.1 & 0.02 & 1352.4 & 236.0 & 1.000 & $\mathrm{~A}^{\prime}$ & 1361.8 & 0.22 \\
\hline \multirow{2}{*}{1308.7} & 130.5 & 0.330 & $\mathrm{~A}^{\prime}$ & 1317.6 & 0.13 & 1364.7 & 142.6 & 0.604 & $\mathrm{~A}^{\prime}$ & 1367.3 & 0.39 \\
\hline & & & & $1325.5^{*}$ & 0.12 & 1402.2 & 11.2 & 0.048 & $\mathrm{~A}^{\prime}$ & 1380.8 & 0.13 \\
\hline 1336.2 & 395.4 & 1.000 & $\mathrm{~A}^{\prime}$ & 1340.2 & 1.00 & 1463.8 & 46.8 & 0.198 & $\mathrm{~A}^{\prime}$ & 1478.7 & 0.08 \\
\hline \multirow[t]{3}{*}{1352.6} & 28.2 & 0.071 & $\mathrm{~A}^{\prime}$ & 1354.4 & 0.02 & 1474.4 & 39.6 & 0.168 & $\mathrm{~A}^{\prime}$ & & \\
\hline & & & & 1358.2 & 0.05 & 1483.8 & 29.0 & 0.123 & $\mathrm{~A}^{\prime}$ & & \\
\hline & & & & 1365.5 & 0.08 & 1508.6 & 48.1 & 0.204 & $\mathrm{~A}^{\prime}$ & 1513.3 & 0.27 \\
\hline 1370.0 & 128.0 & 0.324 & $\mathrm{~A}^{\prime}$ & 1391.6 & 0.38 & 1530.0 & 74.4 & 0.315 & $\mathrm{~A}^{\prime}$ & 1531.3 & 0.24 \\
\hline 1389.4 & 67.5 & 0.171 & $A^{\prime}$ & 1411.8 & 0.18 & 1540.5 & 43.9 & 0.186 & $\mathrm{~A}^{\prime}$ & 1547.9 & 0.15 \\
\hline 1433.7 & 12.4 & 0.031 & $A^{\prime}$ & 1428.0 & 0.05 & 1556.9 & 47.1 & 0.199 & $\mathrm{~A}^{\prime}$ & & \\
\hline 1471.2 & 82.5 & 0.209 & $\mathrm{~A}^{\prime}$ & 1478.0 & 0.04 & 1564.5 & 24.6 & 0.104 & $\mathrm{~A}^{\prime}$ & & \\
\hline 1488.2 & 31.1 & 0.079 & $\mathrm{~A}^{\prime}$ & & & & & & & & \\
\hline 1511.9 & 17.6 & 0.044 & $\mathrm{~A}^{\prime}$ & 1511.9 & 0.06 & & & & & & \\
\hline 1530.2 & 93.2 & 0.236 & $\mathrm{~A}^{\prime}$ & 1537.7 & 0.12 & & & & & & \\
\hline 1543.6 & 32.3 & 0.082 & $\mathrm{~A}^{\prime}$ & 1551.4 & 0.04 & & & & & & \\
\hline 1559.5 & 62.3 & 0.158 & $A^{\prime}$ & 1570.7 & 0.06 & & & & & & \\
\hline \multirow[t]{2}{*}{1573.9} & 50.3 & 0.127 & $\mathrm{~A}^{\prime}$ & 1583.3 & 0.05 & & & & & & \\
\hline & & & & 1599.7 & 0.05 & & & & & & \\
\hline \multicolumn{4}{|c|}{ 3083.1, 3087.6, 3091.2, 3105.0, 3107.1} & & & \multicolumn{4}{|c|}{$3075.4,3089.5,3096.0,3105.9,3108.2$} & & \\
\hline SUM & 30.3 & 0.077 & $\mathrm{~A}^{\prime}$ & & & SUM & 30.0 & 0.127 & $\mathrm{~A}^{\prime}$ & & \\
\hline
\end{tabular}

${ }^{a}$ Data for $\tilde{v}<1600 \mathrm{~cm}^{-1}$ truncated at the $10 \%$ relative intensity level; data for $3120<\tilde{v}<3000 \mathrm{~cm}^{-1}$ truncated at the $1 \%$ relative intensity level. The complete, untruncated tables are available electronically at www.astrochemistry.org/pahdata/index.html. The * indicates strongest member of a multiplet.

TABLE 8: Theoretical and Experimental Band Positions and Intensities for the 7,8-Benzoquinoline and 2-Azapyrene Cations ${ }^{a}$

\begin{tabular}{|c|c|c|c|c|c|c|c|c|c|c|c|}
\hline \multicolumn{6}{|c|}{ 7,8-benzoquinoline } & \multicolumn{6}{|c|}{ 2-azapyrene } \\
\hline \multicolumn{4}{|c|}{ theory } & \multicolumn{2}{|c|}{ experiment } & \multicolumn{4}{|c|}{ theory } & \multicolumn{2}{|c|}{ experiment } \\
\hline $\begin{array}{c}\tilde{v} \\
\left(\mathrm{~cm}^{-1}\right)\end{array}$ & $\begin{array}{c}A \\
\mathrm{~km} / \mathrm{mol}\end{array}$ & $I_{\text {rel }}$ & $\Gamma$ & $\begin{array}{c}\tilde{v} \\
\left(\mathrm{~cm}^{-1}\right)\end{array}$ & $I_{\text {rel }}$ & $\begin{array}{c}\tilde{v} \\
\left(\mathrm{~cm}^{-1}\right)\end{array}$ & $\begin{array}{c}A \\
\mathrm{~km} / \mathrm{mol}\end{array}$ & $I_{\text {rel }}$ & $\Gamma$ & $\begin{array}{c}\tilde{v} \\
\left(\mathrm{~cm}^{-1}\right)\end{array}$ & $I_{\mathrm{rel}}$ \\
\hline 543.7 & 17.0 & 0.137 & $\mathrm{~A}^{\prime}$ & 536.3 & 0.36 & 689.3 & 41.7 & 0.205 & $\mathrm{~B}_{1}$ & 694.8 & 0.15 \\
\hline 606.5 & 8.8 & 0.071 & $\mathrm{~A}^{\prime}$ & 596.6 & 0.14 & 847.5 & 60.1 & 0.295 & $\mathrm{~B}_{1}$ & 855.8 & 0.09 \\
\hline 700.9 & 41.5 & 0.335 & $\mathrm{~A}^{\prime \prime}$ & 698.2 & 0.36 & 918.8 & 35.7 & 0.175 & $\mathrm{~B}_{1}$ & 914.1 & 0.07 \\
\hline 757.7 & 29.5 & 0.238 & $A^{\prime \prime}$ & 757.7 & 0.06 & 978.0 & 24.8 & 0.122 & $\mathrm{~B}_{2}$ & 990.7 & 0.11 \\
\hline 817.8 & 22.5 & 0.181 & $\mathrm{~A}^{\prime \prime}$ & & & 992.4 & 50.4 & 0.247 & $A_{1}$ & 1004.8 & 0.10 \\
\hline 863.1 & 36.9 & 0.298 & $\mathrm{~A}^{\prime \prime}$ & 853.5 & 0.20 & 1254.7 & 77.9 & 0.382 & $\mathrm{~A}_{1}$ & 1259.2 & 0.13 \\
\hline 863.4 & 15.4 & 0.124 & $\mathrm{~A}^{\prime}$ & 870.6 & 0.12 & 1275.6 & 23.2 & 0.114 & $\mathrm{~B}_{2}$ & $1305.1 *$ & 0.70 \\
\hline 999.2 & 43.2 & 0.349 & $A^{\prime}$ & 1003.1 & 0.20 & 1337.7 & 111.6 & 0.547 & $\mathrm{~B}_{2}$ & $1351.7 *$ & 0.33 \\
\hline 1018.4 & 20.7 & 0.167 & $\mathrm{~A}^{\prime \prime}$ & 1012.2 & 0.11 & 1362.8 & 5.1 & 0.025 & $\mathrm{~B}_{2}$ & 1358.7 & 0.25 \\
\hline 1019.6 & 0.7 & 0.006 & $\mathrm{~A}^{\prime \prime}$ & 1024.8 & 0.10 & 1411.7 & 43.0 & 0.211 & $\mathrm{~B}_{2}$ & $1428.0 *$ & 0.31 \\
\hline 1044.2 & 5.5 & 0.045 & $A^{\prime}$ & 1053.0 & 0.10 & 1434.4 & 25.8 & 0.127 & $A_{1}$ & & \\
\hline 1113.0 & 16.6 & 0.134 & $\mathrm{~A}^{\prime}$ & & & 1451.6 & 30.1 & 0.147 & $A_{1}$ & & \\
\hline 1143.6 & 51.1 & 0.413 & $\mathrm{~A}^{\prime}$ & 1139.9 & 0.22 & 1523.0 & 204.0 & 1.000 & $\mathrm{~B}_{2}$ & 1548.7 & 1.00 \\
\hline 1169.1 & 53.3 & 0.430 & $\mathrm{~A}^{\prime}$ & $1159.9 *$ & 0.60 & & & & & & \\
\hline 1205.0 & 43.5 & 0.351 & $\mathrm{~A}^{\prime}$ & $1202.6 *$ & 0.80 & & & & & & \\
\hline 1213.0 & 22.7 & 0.184 & $\mathrm{~A}^{\prime}$ & 1216.5 & 0.08 & & & & & & \\
\hline 1239.1 & 74.8 & 0.604 & $\mathrm{~A}^{\prime}$ & 1230.7 & 0.09 & & & & & & \\
\hline \multirow[t]{3}{*}{1253.0} & 123.4 & 0.996 & $A^{\prime}$ & 1243.1 & 1.00 & & & & & & \\
\hline & & & & 1249.8 & 0.16 & & & & & & \\
\hline & & & & 1259.6 & 0.25 & & & & & & \\
\hline 1304.5 & 53.8 & 0.435 & $\mathrm{~A}^{\prime}$ & 1308.2 & 0.40 & & & & & & \\
\hline 1409.5 & 59.1 & 0.477 & $\mathrm{~A}^{\prime}$ & 1420.5 & 0.14 & & & & & & \\
\hline 1424.3 & 7.2 & 0.058 & $\mathrm{~A}^{\prime}$ & 1431.7 & 0.03 & & & & & & \\
\hline 1467.3 & 67.4 & 0.544 & $A^{\prime}$ & 1439.1 & 0.69 & & & & & & \\
\hline 1484.2 & 9.8 & 0.080 & $A^{\prime}$ & $1490.7 *$ & 0.90 & & & & & & \\
\hline 1508.3 & 11.6 & 0.094 & $\mathrm{~A}^{\prime}$ & 1509.0 & 0.12 & & & & & & \\
\hline 1517.2 & 123.8 & 1.000 & $\mathrm{~A}^{\prime}$ & $1536.3 *$ & 0.92 & & & & & & \\
\hline 1547.4 & 103.0 & 0.832 & $A^{\prime}$ & & & & & & & & \\
\hline 1574.7 & 63.6 & 0.513 & $\mathrm{~A}^{\prime}$ & 1583.1 & 0.09 & & & & & & \\
\hline \multicolumn{4}{|c|}{$3089.1,3111.7$} & & & \multicolumn{4}{|c|}{$3073.7,3090.7$} & & \\
\hline SUM & 6.0 & 0.049 & $\mathrm{~A}^{\prime}$ & & & SUM & 6.1 & 0.030 & $A_{1}, B_{2}$ & & \\
\hline
\end{tabular}

${ }^{a}$ Data for $\tilde{v}<1600 \mathrm{~cm}^{-1}$ truncated at the $10 \%$ relative intensity level; data for $3120<\tilde{v}<3000 \mathrm{~cm}^{-1}$ truncated at the $1 \%$ relative intensity level. The complete, untruncated tables are available electronically at www.astrochemistry.org/pahdata/index.html. The * indicates strongest member of a multiplet. 
TABLE 9: Comparison of the Total Absolute Absorption Intensities of PANHs and Their Corresponding PAHs in Neutral and Cationic Forms in the 1100-500, 1600-1100, and 3150-2950 $\mathrm{cm}^{-1}$ Regions of the Spectrum

\begin{tabular}{|c|c|c|c|c|c|c|c|c|c|}
\hline & \multicolumn{2}{|c|}{$\sum_{1100>\tilde{r}>500} A$} & \multicolumn{2}{|c|}{$\sum_{1600>\tilde{v}>1100} A$} & \multicolumn{2}{|c|}{$\sum_{3150>\tilde{v}>2950} A^{a}$} & & & \\
\hline & \multirow{2}{*}{$\begin{array}{l}\text { neutral } \\
\mathrm{km} / \mathrm{mol}\end{array}$} & \multirow{2}{*}{$\begin{array}{c}\text { cation } \\
\mathrm{km} / \mathrm{mol}\end{array}$} & \multirow{2}{*}{$\begin{array}{c}\text { neutral } \\
\mathrm{km} / \mathrm{mol}\end{array}$} & \multirow{2}{*}{$\begin{array}{c}\text { cation } \\
\mathrm{km} / \mathrm{mol}\end{array}$} & \multirow{2}{*}{$\begin{array}{c}\text { neutral } \\
\mathrm{km} / \mathrm{mol}\end{array}$} & \multirow{2}{*}{$\begin{array}{c}\text { cation } \\
\mathrm{km} / \mathrm{mol}\end{array}$} & \multicolumn{3}{|c|}{ ratios (cation/neutral) } \\
\hline & & & & & & & $\sum_{1100>\tilde{v}>500} A$ & $\sum_{1600>\tilde{v}>1100} A$ & $\sum_{3150>\tilde{v}>2950} A$ \\
\hline \multicolumn{10}{|l|}{ PAHs } \\
\hline phenanthrene & 167 & 260 & 52 & 953 & 199 & 15 & 1.55 & 18.2 & 0.07 \\
\hline pyrene & 176 & 225 & 58 & 525 & 217 & 13 & 1.28 & 9.1 & 0.06 \\
\hline benz $[a]$ anthracene & 204 & 267 & 69 & 1694 & 242 & 44 & 1.31 & 24.5 & 0.18 \\
\hline chrysene & 210 & 297 & 70 & 2064 & 236 & 49 & 1.41 & 29.4 & 0.21 \\
\hline average & & & & & & & 1.39 & 20.3 & 0.13 \\
\hline \multicolumn{10}{|l|}{ PANHs } \\
\hline 7,8-benzoquinoline & 166 & 268 & 126 & 905 & 177 & 11 & 1.62 & 7.2 & 0.06 \\
\hline 2-azapyrene & 171 & 242 & 102 & 616 & 181 & 8 & 1.41 & 6.0 & 0.05 \\
\hline 1-azabenz $[a]$ anth. & 193 & 234 & 176 & 1370 & 221 & 36 & 1.21 & 7.8 & 0.17 \\
\hline 2-azabenz $[a]$ anth. & 194 & 205 & 142 & 1350 & 218 & 34 & 1.05 & 9.5 & 0.15 \\
\hline 1-azachrysene & 198 & 320 & 130 & 1552 & 202 & 37 & 1.62 & 12.0 & 0.18 \\
\hline 2-azachrysene & 210 & 329 & 152 & 2099 & 207 & 34 & 1.57 & 13.8 & 0.17 \\
\hline 4-azachrysene & 206 & 280 & 160 & 1762 & 216 & 36 & 1.36 & 11.0 & 0.17 \\
\hline average & & & & & & & 1.41 & 9.6 & 0.13 \\
\hline
\end{tabular}

${ }^{a}$ The theoretical $\mathrm{CH}$ stretching intensities are not corrected for the expected factor of $\approx 2$ overestimate associated with calculations at the B3LYP/ 4-31G level (see section II.B). ${ }^{3}$

TABLE 10: Rotational Constants and Dipole Moments for Neutral and Cation PANH Species

\begin{tabular}{|c|c|c|c|c|c|c|c|c|c|c|c|c|}
\hline \multirow[b]{2}{*}{ PANH } & \multicolumn{6}{|c|}{ neutral } & \multicolumn{6}{|c|}{ cation } \\
\hline & $\begin{array}{l}\mu_{\mathrm{A}} \\
\text { (D) }\end{array}$ & $\begin{array}{c}\mathrm{A} \\
(\mathrm{GHz})\end{array}$ & $\begin{array}{l}\mu_{\mathrm{B}} \\
\text { (D) }\end{array}$ & $\begin{array}{c}\mathrm{B} \\
(\mathrm{GHz})\end{array}$ & $\begin{array}{l}\mu_{\mathrm{C}} \\
\text { (D) }\end{array}$ & $\begin{array}{c}\mathrm{C} \\
(\mathrm{GHz})\end{array}$ & $\begin{array}{l}\mu_{\mathrm{A}} \\
\text { (D) }\end{array}$ & $\begin{array}{c}\mathrm{A} \\
(\mathrm{GHz})\end{array}$ & $\begin{array}{l}\mu_{\mathrm{B}} \\
\text { (D) }\end{array}$ & $\begin{array}{c}\mathrm{B} \\
(\mathrm{GHz})\end{array}$ & $\begin{array}{l}\mu_{\mathrm{C}} \\
\text { (D) }\end{array}$ & $\begin{array}{c}\mathrm{C} \\
(\mathrm{GHz})\end{array}$ \\
\hline 7,8-benzoquinoline & 0.7 & 1.609 & -1.71 & 0.568 & 0 & 0.420 & -0.68 & 1.626 & -2.32 & 0.563 & 0 & 0.418 \\
\hline 2-azapyrene & -3.16 & 1.019 & 0 & 0.555 & 0 & 0.359 & -3.59 & 1.027 & 0 & 0.551 & 0 & 0.359 \\
\hline 1-azabenz $[a]$ anth. & 0.92 & 1.164 & 1.39 & 0.262 & 0 & 0.214 & -1.39 & 1.166 & 1.76 & 0.262 & 0 & 0.214 \\
\hline 2-azabenz $[a]$ anth & -1.77 & 1.170 & 2.43 & 0.257 & 0 & 0.210 & -4.61 & 1.173 & 2.88 & 0.256 & 0 & 0.210 \\
\hline 1-azachrysene & 1.44 & 1.267 & 1.95 & 0.264 & 0 & 0.218 & 3.11 & 1.279 & 2.2 & 0.261 & 0 & 0.217 \\
\hline 2-azachrysene & 3.36 & 1.271 & 0.21 & 0.262 & 0 & 0.217 & 4.34 & 1.283 & 0.36 & 0.259 & 0 & 0.216 \\
\hline 4-azachrysene & -0.48 & 1.259 & -1.82 & 0.268 & 0 & 0.221 & 1.38 & 1.270 & -1.76 & 0.265 & 0 & 0.220 \\
\hline
\end{tabular}

sponding aromatic hydrocarbon species. Although the $\mathrm{CN}, \mathrm{CC}$, and $\mathrm{CH}$ vibrational motions are heavily mixed in the vibrational modes of the neutral and cationic PANH species considered in this study, several modes in the $1100-1000 \mathrm{~cm}^{-1}$ region were found to carry significant contributions from $\mathrm{CN}$ stretching and CNC in-plane bending while several modes in the 600-500 $\mathrm{cm}^{-1}$ region were found to carry significant contributions from CNC out-of-plane warping motions.

Calculated dipole moments and rotational constants are also presented for both the neutral and cationic states of these polar species. The rotational parameters for the PANHs studied here indicate that these species will exhibit centimeter-wavelength pure rotational spectra in the electromagnetic spectrum.

Acknowledgment. This project was performed, in part, using compounds provided by the National Cancer Institute's Chemical Carcinogen Reference Standards Repository operated under contract by Midwest Research Institute, No. N02-CB-07008.
The authors also wish to acknowledge the expert technical support of Bob Walker. Dr. Mattioda gratefully acknowledges the support of the National Research Council's Research Associateship Program. Dr. M. Rosi thanks the CNR for a shortterm fellowship. This work was fully supported by NASA's Laboratory Astrophysics and Long Term Space Astrophysics programs, under grants \#188-44-57-01 and \#399-20-01-05. Special acknowledgment goes to the reviewers of this article whose insightful comments aided in the clarification of several issues.

\section{Appendix}

Comparison of experimental and theoretical data for 1-azabenz $[a]$ anthracene (Figures 11 and 12). Theoretical data were fitted to a Gaussian band shape utilizing a half-width at halfheight of $3 \mathrm{~cm}^{-1}$. Agreement between experimental and theoretical data for the remainder of the PANHs in this investigation were similar to 1 -azabenz $[a]$ anthracene.

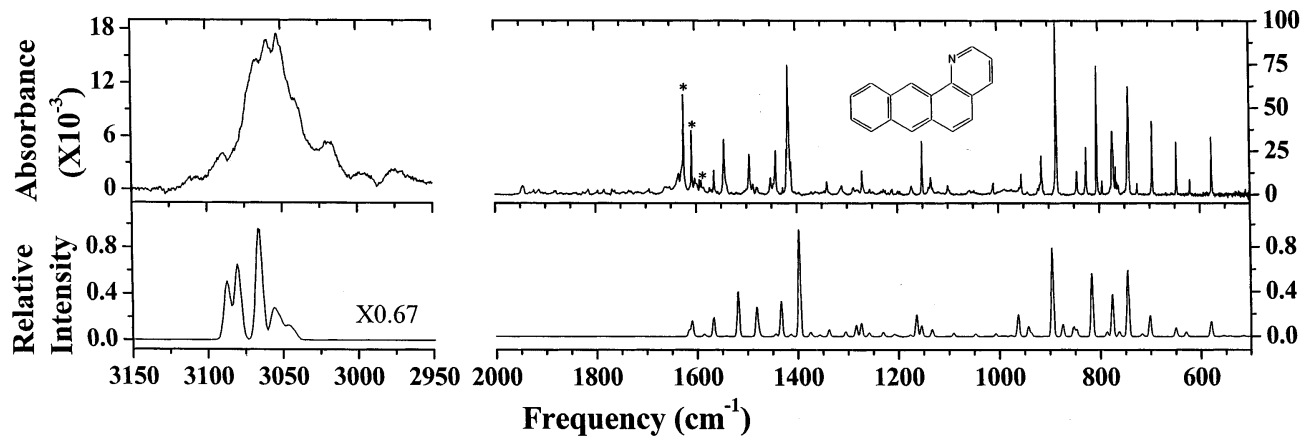

Figure 11. Comparison of the experimental (top) and theoretical (bottom) spectra for neutral 1-azabenz $[a]$ anthracene. Water bands are indicated by an *. 


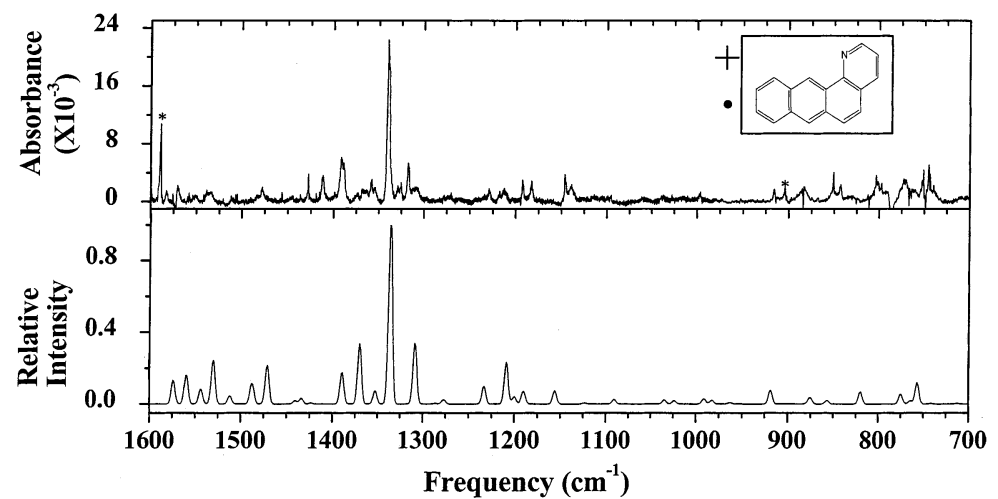

Figure 12. Comparison of experimental (top) and theoretical (bottom) spectra of the 1-azabenz $[a]$ anthracene cation. Photoproducts not associated with the PANH are indicated by an *.

\section{References and Notes}

(1) Cox, P.; Kessler, M. F. The Universe as Seen by ISO, Vol 2, ESA SP-427; ESTEC, ESA Publications Division: Noordwijk, The Netherlands, 1999.

(2) Langhoff, S. R. J. Phys. Chem. 1996, 100, 2819.

(3) (a) Bauschlicher, C. W.; Langhoff, S. R. Spectrochim. Acta A 1997 53, 1225. (b) Bauschlicher, C. W., Jr.; Langhoff, S. R.; Sandford, S. A.; Hudgins, D. M. J. Phys. Chem. A 1997, 101, 2414. (c) Langhoff, S. R.; Bauschlicher, C. W., Jr.; Hudgins, D. M.; Sandford, S. A.; Allamandola, L. J. J. Phys. Chem. A 1998, 102, 1632. (d) Bauschlicher, C. W. Chem. Phys. 1998, 233, 29. (e) Bauschlicher, C. W.; Langhoff, S. R. Chem. Phys. 1998, 234, 79. (f) Bauschlicher, C. W. Chem. Phys. 1998, 234, 87. (g) Bauschlicher, C. W. Chem. Phys. 1998, 234, 87. (h) Bauschlicher, C. W.; Bakes, E. L. O. Chem. Phys. 2000, 262, 285.

(4) (a) Talbi, D.; Pauzat, F.; Ellinger, Y. Astron. Astrophys. 1993, 268 805. (b) de Frees, D. J.; Miller, M. D.; Talbi, D.; Pauzat, F.; Ellinger, Y. Ap. J. 1993, 408, 530. (c) Pauzat, F.; Talbi, D.; Ellinger, Y. Astron. Astrophys. 1995, 293, 263. (d) Pauzat, F.; Talbi, D.; Ellinger, Y. MNRAS 1999, 304, 241. (e) Pauzat, F.; Ellinger, Y. MNRAS 2001, 324, 355.

(5) See, for example: (a) Pauzat, F.; Talbi, D.; Ellinger, Y. Astron. Astrophys. 1997, 319, 318. (b) Hudgins, D. M.; Bauschlicher, C. W.; Allamandola, L. J. Spectrochim. Acta A 2001, 57, 907.

(6) Halasinski, T.; Hudgins, D. M.; Salama, F.; Allamandola, L. J.; Bally, T. J. Phys. Chem. 2000, 104, 7484.

(7) (a) Szczepanski, J.; Roser, D.; Personette, W.; Eyring, M.; Pellow, R.; Vala, M. J. Phys. Chem. 1992, 96, 7876. (b) Szczepanski, J.; Vala, M. Nature 1993, 363, 699. (c) Szczepanski, J.; Vala, M. Ap. J. 1993, 414 179. (d) Szczepanski, J.; Chapo, C.; Vala, M. Chem Phys. 1993, 205, 434 (e) Szczepanski, J.; Vala, M.; Talbi, D.; Parisel, O.; Ellinger, Y. J. J. Chem Phys. 1993, 98, 4494. (f) Vala, M.; Szczepanski, J.; Pauzat, F.; Parisel, O.; Talbi, D.; Ellinger, Y. J. J. Phys. Chem. 1994, 98, 9187. (g) Szczepanski, J.; Wehlburg, C.; Vala, M. Chem. Phys. Lett 1995,. 232, 221. (h) Szczepanski, J.; Drawdy, J.; Wehlburg, C.; Vala, M. Chem. Phys. Lett. 1995, $245,539$.

(8) (a) Hudgins, D.; Sandford, S. A.; Allamandola, L. J J. Phys. Chem. 1994, 98, 4243. (b) Hudgins, D. M.; Allamandola, L. J. J. Phys. Chem 1995, 99, 3033. (c) Hudgins, D. M.; Allamandola, L. J. J. Phys. Chem. 1995, 99, 8978. (d) Hudgins, D. M.; Allamandola, L. J. J. Phys. Chem. A 1997, 101, 3472. (e) Hudgins, D. M.; Sandford, S. A. J. Phys. Chem. A
1998, 102, 329. (f) Hudgins, D. M.; Sandford, S. A. J. Phys. Chem. A 1998 102, 344. (g) Hudgins, D. M.; Sandford, S. A. J. Phys. Chem. A 1998, 102, 353. (h) Hudgins, D. M.; Bauschlicher, C. W., Jr.; Allamandola, L. J.; Fetzer, J. C. J. Phys. Chem. A 1998, 104, 3655.

(9) Bauschlicher, C. W., Jr.; Hudgins, D. M.; Allamandola, L. J. Theor Chem. Acc. 1999, 103, 154

(10) (a) Schlemmer, S.; Cook, D. J.; Harrison, J. A.; Wurfel, B.; Chapman, W.; Saykally, R. J. Science 1994, 265, 1686. (b) Cook, D. J.; Saykally, R. J. Ap. J. 1998, 493, 793. (c) Wagner, D. R.; Kim, H.-S.; Saykally, R. J. Ap. J. 2000, 545, 854. (d) Kim, H.-S.; Wagner, D. R.; Saykally, R. J. Ap. J. (in press, 2002).

(11) (a) Piest, J. A.; von Helden, G.; Meijer, G. Ap. J. 1999, 520, L75. (b) Piest, J. A.; Oomens, J.; Bakker, J.; von Helden, G.; Meijer, G. Spectrochim. Acta A 2001, 57A, 717. (c) Oomens, J.; van Roij, A. J. A.; Meijer, G.; von Helden, G. Ap. J. 2000, 542, 404.

(12) Becke, A. D. J. Chem. Phys. 1993, 98, 5648.

(13) Stephens, P. J.; Devlin, F. J.; Chabalowski, C. F.; Frisch, M. J. J. Phys. Chem. 1994, 98, 11623.

(14) Frisch, M. J.; Pople, J. A.; Binkley, J. S. J. Chem. Phys. 1984, 80, 3265 and references therein.

(15) Frisch, M. J.; Trucks, G. W.; Schlegel, H. B.; Scuseria, G. E.; Robb, M. A.; Cheeseman, J. R.; Zakrzewski, V. G.; Montgomery, J. A., Jr.; Stratmann, R. E.; Burant, J. C.; Dapprich, S.; Millam, J. M.; Daniels, A. D.; Kudin, K. N.; Strain, M. C.; Farkas, O.; Tomasi, J.; Barone, V.; Cossi, M.; Cammi, R.; Mennucci, B.; Pomelli, C.; Adamo, C.; Clifford, S.; Ochterski, J.; Petersson, G. A.; Ayala, P. Y.; Cui, Q.; Morokuma, K.; Malick, D. K.; Rabuck, A. D.; Raghavachari, K.; Foresman, J. B.; Cioslowski, J Ortiz, J. V.; Stefanov, B. B.; Liu, G.; Liashenko, A.; Piskorz, P.; Komaromi, I.; Gomperts, R.; Martin, R. L.; Fox, D. J.; Keith, T.; Al-Laham, M. A.; Peng, C. Y.; Nanayakkara, A.; Gonzalez, C.; Challacombe, M.; Gill, P. M. W.; Johnson, B. G.; Chen, W.; Wong, M. W.; Andres, J. L.; Head-Gordon, M.; Replogle, E. S.; Pople, J. A. Gaussian 98, revision A.11; Gaussian, Inc.: Pittsburgh, PA, 1998.

(16) Flükiger, P.; Lüthi, H. P.; Portmann, S.; Weber, J. MOLEKEL 4.2; Swiss Center for Scientic Computing: Manno, Switzerland, 2000-2002. Portmann, S.; Lüthi, H. P. MOLEKEL: An Interactive Molecular Graphics Tool. CHIMIA 2000, 54, 766-770.

(17) Townes, C. H.; Schawlow, A. L. Microwave Spectroscopy; Dover Publications: New York, 1975. 